\title{
Angioblast Derived from ES Cells Construct Blood Vessels and Ameliorate Diabetic Polyneuropathy in Mice
}

\author{
Tatsuhito Himeno, ${ }^{1,2}$ Hideki Kamiya, ${ }^{3,4}$ Keiko Naruse, ${ }^{5}$ Zhao Cheng, \\ Sachiko Ito, ${ }^{2}$ Taiga Shibata, ${ }^{1}$ Masaki Kondo, ${ }^{1,2}$ Jiro Kato, ${ }^{1}$ \\ Tetsuji Okawa, ${ }^{1,2}$ Atsushi Fujiya, ${ }^{1,6}$ Hirohiko Suzuki, ${ }^{2}$ Tetsutaro Kito, ${ }^{2}$ \\ Yoji Hamada, ${ }^{6}$ Yutaka Oiso, ${ }^{1}$ Kenichi Isobe, ${ }^{2}$ and Jiro Nakamura ${ }^{1,4}$ \\ ${ }^{1}$ Department of Endocrinology and Diabetes, Nagoya University Graduate School of Medicine, 65 Tsurumai-cho, \\ Showa-ku, Nagoya 466-8550, Japan \\ ${ }^{2}$ Department of Immunology, Nagoya University Graduate School of Medicine, 65 Tsurumai-cho, Showa-ku, Nagoya 466-8550, Japan \\ ${ }^{3}$ Department of Chronic Kidney Disease Initiatives, Nagoya University Graduate School of Medicine, 65 Tsurumai-cho, \\ Showa-ku, Nagoya 466-8550, Japan \\ ${ }^{4}$ Division of Diabetes, Department of Internal Medicine, Aichi Medical University School of Medicine, 21 Karimata, \\ Yazako, Nagakute, Aichi 480-1195, Japan \\ ${ }^{5}$ Department of Internal Medicine, School of Dentistry, Aichi Gakuin University, 1-100 Kusumoto-cho, \\ Chikusa-ku, Nagoya 464-8650, Japan \\ ${ }^{6}$ Department of Metabolic Medicine, Nagoya University Graduate School of Medicine, 65 Tsurumai-cho, \\ Showa-ku, Nagoya 466-8550, Japan
}

Correspondence should be addressed to Hideki Kamiya; hkamiya@aichi-med-u.ac.jp

Received 16 December 2014; Revised 24 March 2015; Accepted 25 March 2015

Academic Editor: Raffaele Marfella

Copyright (C) 2015 Tatsuhito Himeno et al. This is an open access article distributed under the Creative Commons Attribution License, which permits unrestricted use, distribution, and reproduction in any medium, provided the original work is properly cited.

\begin{abstract}
Background. Although numerous reports addressing pathological involvements of diabetic polyneuropathy have been conducted, a universally effective treatment of diabetic polyneuropathy has not yet been established. Recently, regenerative medicine studies in diabetic polyneuropathy using somatic stem/progenitor cell have been reported. However, the effectiveness of these cell transplantations was restricted because of their functional and numerical impairment in diabetic objects. Here, we investigated the efficacy of treatment for diabetic polyneuropathy using angioblast-like cells derived from mouse embryonic stem cells. Methods and Results. Angioblast-like cells were obtained from mouse embryonic stem cells and transplantation of these cells improved several physiological impairments in diabetic polyneuropathy: hypoalgesia, delayed nerve conduction velocities, and reduced blood flow in sciatic nerve and plantar skin. Furthermore, pathologically, the capillary number to muscle fiber ratios were increased in skeletal muscles of transplanted hindlimbs, and intraepidermal nerve fiber densities were ameliorated in transplanted plantar skin. Transplanted cells maintained their viabilities and differentiated to endothelial cells and smooth muscle cells around the injection sites. Moreover, several transplanted cells constructed chimeric blood vessels with recipient cells. Conclusions. These results suggest that transplantation of angioblast like cells induced from embryonic stem cells appears to be a novel therapeutic strategy for diabetic polyneuropathy.
\end{abstract}

\section{Introduction}

Large prospective clinical studies have shown a strong relationship between hyperglycemia and diabetic microvascular complications in both type 1 diabetes and type 2 diabetes [1-3]. Several hypotheses about diabetic complications have been formulated: increased polyol pathway flux [4], increased advanced glycation end-product formation [5-10], increased 
PKC activation [11-14], and increased hexosamine pathway flux [15]. The involvement of these chronic hyperglycemiamediated metabolic aberrances has also been proven in diabetic polyneuropathy (DPN) [16, 17].

DPN is the most common peripheral neuropathy, and degeneration of distal axons of peripheral neurons progresses slowly and symmetrically in DPN. Along with HbAlc and duration of diabetes, baseline cardiovascular disease and smoking have been indicated as risk factors for DPN [18]. Additionally, it has been reported that, in DPN, the thickness of endoneurial microvessels of sural nerves increased [19,20] while endoneurial nutritive blood flow of sciatic nerves decreased $[21,22]$. The vascular dysfunction in DPN is considered to be one of the most important pathologies.

Evidence accumulated in the past two decades indicates that peripheral blood cells contain a subpopulation with properties similar to embryonic angioblast [23-26]. These cells could be differentiated into mature endothelial cells. Therefore, these cells were termed "endothelial progenitor cells" (EPCs). It has been attested that EPCs migrated to ischemia lesions and played a pivotal role in vascular endothelial function and angiogenesis [27, 28]. Several studies have demonstrated the interventional effects of EPC transplantation on myocardial ischemia/infarction and preventive effects on plaque progression in mice $[29,30]$. However, the number of circulating EPCs decreased in diabetic patients, and EPCs isolated from diabetic mice exhibited decreased functions, including migration, adhesion, and tube formation [31-35]. Recent studies have shown that oxidative stress, elevated by hyperglycemia, decreased EPC survival through inhibition of cell proliferation and NO production [36,37]. Marrotte et al. reported that EPCs isolated from diabetic mice were less effective than EPCs from nondiabetic mice at accelerating wound closure in diabetic mice [38]. They also demonstrated that decreased expression of manganese superoxide dismutase in EPCs obtained from diabetic mice contributes to impairment of wound healing. These functional and metabolic obstacles inhibit clinical applications of EPCs on diabetic vascular complications.

In current regenerative medicines, cells used for transplantations are expected to have two primary abilities: one is differentiation abilities to specific cells or tissues and the other is paracrine supportive effects to impaired tissues. Certain cell transplantation therapies have already been applied to some clinical diseases using various stem/progenitor cells from somatic tissues: EPC, mesenchymal stem cell (MSC), skin-derived precursor cell, neural stem cell, and neural crest stem cell $[39,40]$. In particular, MSC has been applied to the treatment of certain diseases: myocardial infarction [41], stroke [42], and graft versus host disease [43]. Although the paracrine mechanisms in damaged tissues and the immunomodulatory properties of MSC have been proven in these clinical applications, the probability of survival of transplanted MSCs is small and the therapeutic effects on a longterm basis remain unclear.

Recent advances of stem cell biology permit the derivation of induced pluripotent stem (iPS) cell lines at an individual level in mammalians including humans. Although ES cells are attractive in their pluripotency and availability of intact and stable undifferentiated status, there are difficulties in clinical applications of human ES cells because of safety and ethics. Although there are still safety problems that have to be solved, the autologous use of human iPS cells may resolve ethical issues. In this circumstance, problematic issues with using ES cells could be circumvented by employing an equivalent substance, iPS cells, in the future. However, there is no standard for iPS cells: the number of obtainable iPS cell lines is vast and the methods to obtain them are innumerable. Additionally, there are heterogeneous properties among the iPS cells. Therefore, we utilized ES cells in this current study.

We have reported that transplantation of EPCs ameliorated DPN [44]. We hypothesized that if angioblast-like cells could be obtained from iPS or ES cells, these cells would operate like EPCs and restore numerous impairments in DPN. It has been shown that the vascular endothelial growth factor receptor-2 (VEGFR2, known also Flk1) was expressed in angioblasts and its function is essential for the differentiation of endothelial cells and hematopoietic cells [45]. Therefore, Flk1 positive $\left(\mathrm{Flkl}^{+}\right)$cells derived from ES cells may have similar characteristics to angioblasts and similar or additional functions of EPCs in adults. This is the first report that demonstrates the therapeutic effects of transplantation of angioblast-like cells derived from mouse ES cells on DPN.

\section{Research Design and Methods}

2.1. Cell Culture. BRC6, mouse ES cells derived from C57BL/6 female embryo, and B6G02, mouse ES cells expressing GFP derived from a C57BL/6 male embryo, were obtained from the Riken Cell Bank (Ibaragi, Japan). ES cells were maintained in DMEM (Invitrogen, Van Allen Way Carlsbad, CA) containing 10\% Knockout Serum Replacement (Invitrogen), $1 \%$ FBS (Sigma-Aldrich, St. Louis, MO), nonessential amino acids (Invitrogen), $5.5 \mathrm{mmol} / \mathrm{L}$ 2-mercaptoethanol (GIBCO, Burlington, $\mathrm{ON}$ ), $50 \mathrm{U} / \mathrm{mL}$ penicillin (GIBCO), and $50 \mathrm{mg} /$ $\mathrm{mL}$ streptomycin (GIBCO) on feeder layers of mitomycin Cinactivated SNL76/7 cells (the European Collection of Cell Cultures, Salisbury, UK), which were clonally derived from an STO cell line transfected with a G418 resistance cassette and a leukemia inhibitory factor expression construct [46]. The STO cells were established from fibroblasts derived from male and female embryos.

Cell differentiation was induced as previously described [47]. In brief, a differentiation medium ( $\alpha$-MEM (Invitrogen) supplemented with $10 \% \mathrm{FBS}$ and $5 \times 10^{-5} \mathrm{~mol} / \mathrm{L} 2$-mercaptoethanol) was used for ES cell differentiation. For the induction, ES cells were plated at $1.7 \times 10^{3}$ cells $/ \mathrm{cm}^{2}$ in the differentiation medium on gelatin-coated dishes, which were coated with $0.1 \%$ gelatin (Sigma-Aldrich) solution and cultured for 4 days.

Immortalized Schwann cells (IMS32), established by a long-term culture of adult mouse DRGs and peripheral nerves [48], were a kind gift from Dr. Watabe. IMS32s were cultured in DMEM (Sigma-Aldrich) containing $5.5 \mathrm{mM} \mathrm{D-}$ glucose, penicillin- $(100 \mathrm{U} / \mathrm{mL})$ streptomycin $(100 \mathrm{mg} / \mathrm{mL})$, and 5\% FBS (Moregate Biotech, Bulimba QLD, Australia). PA6 cells, a type of mouse MSC, were obtained from 
the Riken Cell Bank. The PA6 cells were cultured in $\alpha$-MEM supplemented with $10 \% \mathrm{FBS}$ and $5 \times 10^{-5} \mathrm{~mol} / \mathrm{L} 2$-mercaptoethanol.

2.2. Cell Sorting. Differentiated cells were detached using Accutase (Sigma-Aldrich) after a 4-day culture. Dissociated cells were reacted with Allophycocyanin conjugated antimouse Flk1 antibody (eBioscience, San Diego, CA), followed by sorting with a magnetic cell separation system (MACS) (Miltenyi Biotec, Bergisch Gladbach, Germany). The purity of the sorted cell population was confirmed in a fluorescenceactivated cell sorting (FACS) analysis (BD FACS Canto, BD, Franklin Lakes, NJ). A portion of the separated cells was transferred to RNAlater Solution (Invitrogen) followed by a freezing preservation for reverse-transcription PCR (RTPCR).

2.3. In Vitro Induction of Endothelial Cell and Smooth Muscle Cell. Sorted Flk1 ${ }^{+}$cells were plated on gelatin-coated dishes in the differentiation medium. For induction to an endothelial cell, differentiation medium supplemented with $100 \mathrm{ng} /$ mL human VEGF $_{165}$ (R\&D Systems, Minneapolis, MN) was used. The medium was replaced every 2 days. After a 4-day culture, cells were fixed with 4\% PFA (Wako Pure Chemical, Osaka, Japan) for 20 minutes at $4^{\circ} \mathrm{C}$.

Then, specimens were blocked with 3\% goat serum (Vector Laboratories, Burlingame, CA) with PBS (GIBCO) for 30 minutes at room temperature, and the following primary antibodies were applied to the sections at $4^{\circ} \mathrm{C}$ overnight: rabbit polyclonal anti- $\alpha$-SMA antibody $(1: 200$; Santa Cruz Biotechnology Inc., Santa Cruz, CA) or rabbit polyclonal anti-PECAM antibody $(1: 200$; Santa Cruz Biotechnology Inc.). After washing, the following secondary antibodies were loaded for 1 hour at room temperature in a dark box: Alexa Fluor 488-coupled goat anti-rabbit IgG antibody (1:200; Invitrogen) or Alexa Fluor 594-coupled goat anti-rabbit antibody (1:300; Invitrogen). Finally, nucleus staining was performed using DAPI (Merck, Tokyo, Japan). The stained sections were observed using a fluorescence microscope (BX51, Olympus Optical, Tokyo, Japan) and images were obtained by a CCD camera (DP70, Olympus Optical).

2.4. Tube Formation Assay. For the tube formation assay, the cells separated by MACS were plated on 4-well slides (Iwaki Glass, Tokyo, Japan) coated thickly with BD Matrigel Basement Membrane Matrix (250 $\mu \mathrm{L}$, Becton-Dickinson Co., Franklin Lakes, NJ) at $3 \times 10^{4}$ cells $/ \mathrm{cm}^{2}$, following culture for 48 hours in EBM-2 medium with EGM-2 Bulletkit (LONZA, Basel, Switzerland). After the culture, cells were fixed with $4 \%$ PFA and stained with Alexa Fluor 594 conjugated isolectin GS-IB4 (Invitrogen) and DAPI (Merck). The tube formations were assessed with a fluorescence microscope (BX51, Olympus Optical) and images were obtained by a CCD camera (DP70, Olympus Optical).

2.5. Animals and Induction of Diabetes. Five-week-old male C57BL/6 mice (Chubu Kagaku Shizai, Nagoya, Japan) with an initial body weight of 24-26g were allowed to adapt to the experimental animal facility for 7 days. The animals were housed in an aseptic animal room under controlled light/dark and temperature conditions with food and water available ad libitum. Diabetes was induced by intraperitoneal injection (i.p.) of streptozotocin (STZ) $(150 \mathrm{mg} / \mathrm{kg}$; Sigma-Aldrich). Control mice received an equal volume of citric acid buffer (Wako). One week after STZ administration, the mice with plasma glucose concentrations of $>16 \mathrm{mmol} / \mathrm{L}$ were defined as diabetic mice. Twelve weeks after the induction of diabetes, $1 \times 10^{5}$ cells/limb of purified Flk $1^{+}$cells in $0.2 \mathrm{~mL}$ saline were injected into the right thigh and soleus muscles of both the normal and the diabetic mice. The left hindlimb muscles were treated with saline alone. Four weeks later, the following parameters were bilaterally measured. Before transplantation of Flk1 ${ }^{+}$cells, fasting blood glucose levels and hemoglobin Alc were examined by a FreeStyle Freedom Glucose Meter (Nipro, Osaka, Japan) and a RAPIDIA Auto HbAlc-L assay kit using latex agglutination (Fujirebio Inc., Tokyo, Japan), respectively. The Nagoya University Institutional Animal Care and Use Committee approved the protocols of this experiment.

\subsection{Measurement of Current Perception Thresholds (CPTs)} Using a Neurometer. To determine a nociceptive threshold, CPTs were measured in 12- and 16-week diabetic and agematched normal mice using a CPT/LAB Neurometer (Neurotron, Denver, CO), according to the method by Shibata et al. [49] with minor modifications. The electrodes (SRE0405-8; Neurotron) for stimulation were attached to plantar surfaces of the mice. Each mouse was kept in a Ballman cage (Natsume Seisakusho, Tokyo, Japan) suitable for light restraint to keep the mice awake. Three transcutaneous-sinewave stimuli with different frequencies $(2000,250$, and $5 \mathrm{~Hz}$ ) were applied to the plantar surfaces of the mice to determine the CPT of sensory perceptions (pressure, pain, and pain and temperature, resp.). The intensity of each stimulation was automatically increased in gradual increments $(0.01 \mathrm{~mA}$ for 5 and $250 \mathrm{~Hz}$ and $0.02 \mathrm{~mA}$ for $2000 \mathrm{~Hz}$ ). The minimum intensity at which each mouse withdrew its paw was defined as the CPT. Six consecutive measurements were conducted at each frequency.

2.7. Nerve Conduction Velocities (NCVs). After intraperitoneal injection of sodium pentobarbital ( $5 \mathrm{mg} / 100 \mathrm{~g}$, Kyoritsuseiyaku Corporation, Tokyo, Japan), mice were placed on a heated pad in a room maintained at $25^{\circ} \mathrm{C}$ to ensure a constant rectal temperature of $37^{\circ} \mathrm{C}$. Motor nerve conduction velocity (MNCV) was determined between the ankle and sciatic notch using a Neuropak NEM-3102 instrument (Nihon-Koden, Osaka, Japan), as previously described $[42,49,50]$. The sensory nerve conduction velocity (SNCV) was measured between the knee and ankle with retrograde stimulation.

2.8. Blood Flows of Sciatic Nerve and Plantar Skin. After evaluation of the MNCV and SNCV, blood flows of the sciatic nerve and the plantar skin were measured by laser Doppler flowmetry (FLO-N1; Omegawave Inc, Tokyo, Japan). To determine sciatic nerve blood flow, the thigh skin of 
TABle 1: Primer sequences.

\begin{tabular}{|c|c|c|c|}
\hline Accession number & Gene & Forward primer $\left(5^{\prime} \rightarrow 3^{\prime}\right)$ & Reverse primer $\left(3^{\prime} \rightarrow 5^{\prime}\right)$ \\
\hline NM_001025250.3 & Vegfa & CAGGCTGCTGTAACGATGAA & TTTCTTGCGCTTTCGTTTTT \\
\hline NM_008006.2 & Fgf2 & GTGGATGGCGTCCGCGAGAA & ACCGGTTGGCACACACTCCC \\
\hline NM_008808.3 & Pdgfa & GAGATACCCCGGGAGTTGAT & TCTTGCAAACTGCAGGAATG \\
\hline NM_001048139.1 & Bdnf & GCCACCGGGGTGGTGTAAGC & CATGGGTCCGCACACCTGGG \\
\hline NM_001112698.1 & Ngf & GTGAAGATGCTGTGCCTCAA & GCGGCCAGTATAGAAAGCTG \\
\hline NM_010275.2 & Gdnf & CGGACGGGACTCTAAGATGA & CGTCATCAAACTGGTCAGGA \\
\hline NM_001164034.1 & $\mathrm{Ntf3}$ & CGAACTCGAGTCCACCTTTC & AGTCTTCCGGCAAACTCCTT \\
\hline NM_170786.2 & Cntf & GCAATCACCTCTGACССТTC & ACGGTAAGCCTGGAGGTTCT \\
\hline NM_010612.2 & $\mathrm{Kdr}$ & GGCGGTGGTGACAGTATCTT & GTCACTGACAGAGGCGATGA \\
\hline NM_011587.2 & Tiel & TCAACTGCAGCTCCAAAATG & TGACAGCTCTGTCCAAAACG \\
\hline NM_013690.2 & Tek & AAGCATGCCCATCTGGTTAC & GTAGGTAGTGGCCACCCAGA \\
\hline NM_001032378.1 & Pecam1 & ATGACCCAGCAACATTCACA & AAAACGCTTGGGTGTCATTC \\
\hline NM_009868.4 & Cdh5 & ACCGGATGACCAAGTACAGC & TTCTGGTTTTCTGGCAGCTT \\
\hline NM_010228.3 & Flt1 & CCAAGGCCTCCATGAAGATA & ATACTGTCAGGGGCTGGTTG \\
\hline NM_009309.2 & $\mathrm{T}$ & GGGGTATTCCCAATGGGGGTGGC & GCCAGGCACTCCGAGGCTAGA \\
\hline NM_011527.2 & Tall & GTCTCTCAGCGAGAGCCGGGA & CGCTCCGTCATCCTGGGGCATA \\
\hline NM_011355.1 & Sfpil & TCCCATGGTGCCACCCCACA & TTGCTGCCTGTCTCCCCGTG \\
\hline NM_001142335.1 & Lmo2 & TGGATGAGGTGCTGCAGATA & GGATGCACAGAGACCATCCT \\
\hline NM_007393.3 & Actb & CATCCGTAAAGACCTCTATGCCAAC & ATGGAGCCACCGATCCACA \\
\hline
\end{tabular}

an anesthetized mouse was cut along femur and then an incision through the fascia was carefully performed to expose the sciatic nerve. Five minutes after this procedure, the blood flow was measured by a laser Doppler probe placed $1 \mathrm{~mm}$ above the nerve. The skin blood flow was determined by the mean of the flow at 3 spots. During this measurement, the mouse was placed on a heated pad in a room maintained at $25^{\circ} \mathrm{C}$ to ensure a constant rectal temperature of $37^{\circ} \mathrm{C}$.

2.9. Tissue Collection. Four weeks after the transplantation, mice were sacrificed by an overdose of pentobarbital $(10 \mathrm{mg} /$ $100 \mathrm{~g})$. Soleus muscles and plantar skin tissue were obtained from normal and diabetic mice. Some tissues were snapfrozen in liquid nitrogen followed by preservation at $-80^{\circ} \mathrm{C}$ until use, and others were transferred to RNAlater Solution (Invitrogen) followed by freezing preservation for RT-PCR.

2.10. Real-Time RT-PCR. RNA was extracted from frozen samples of cells and tissues using ISOGEN (Nippon Gene, Toyama, Japan) according to the manufacturer's instructions and the concentrations were quantified spectrophotometrically (NanoDrop ND-100, Nanodrop Tec., Wilmington, DE). DNA was digested with RNase-free DNase I (Wako Pure Chemical), which was then inactivated by incubation at $80^{\circ} \mathrm{C}$ for $10 \mathrm{~min}$.

Starting from $1 \mu \mathrm{g}$ of RNA, cDNA was synthesized using ReverTra Ace (TOYOBO, Osaka, Japan) according to the manufacturer's descriptions. Primers were designed by Primer3 software (http://frodo.wi.mit.edu/) and tested for specificity with NCBI-BLAST (http://www.ncbi.nlm.nih .gov/tools/primer-blast/). Real-time quantitative RT-PCR was performed and monitored using Mx3000P QPCR System (STRATAGENE, La Jolla, California, USA). The PCR master mix was based on SYBR Green PCR Master Mix (Applied Biosystems, Foster City, CA). In reaction wells, cDNA samples ( $5 \mu \mathrm{L}$ for a total volume of $25 \mu \mathrm{L}$ per reaction) were analyzed for the gene of interest. All data were normalized to an internal standard, $\beta$-actin. The PCR products were analyzed by agarose gel (Takara Bio Inc., Otsu, Japan)/ethidium bromide (Sigma-Aldrich) to confirm these predicted lengths. Relative quantity was calculated by the $\Delta \Delta \mathrm{Ct}$ method. The primer sequences are shown in Table 1.

2.11. Immunohistochemistry. Four weeks after the transplantation, the mice were anesthetized with sodium pentobarbital ( $5 \mathrm{mg} / 100 \mathrm{~g}$ ) and perfused with $50 \mathrm{~mL}$ of $4 \%$ PFA fixative. After perfusion, soleus muscles and plantar skin samples were excised and fixed in $4 \% \mathrm{PFA}$ at $4^{\circ} \mathrm{C}$ overnight. Specimens were immersed in PBS containing 20\% sucrose (Wako) embedded within an O.C.T. compound (Sakura Finetechnical, Tokyo, Japan) and cut into $5 \mu \mathrm{m}$ sections with a sliding cryostat (CM1800, Leica Microsystems AG, Wetzler, Germany). After 5 minutes of microwave irradiation in citrate buffer $(\mathrm{pH}$ 6.0, Wako), the cryostat sections were blocked with $3 \%$ goat serum with PBS for 30 minutes at room temperature. Prior to being stored at $4^{\circ} \mathrm{C}$ overnight, the following primary antibodies were applied to the sections: rabbit polyclonal anti-protein-gene-product 9.5 (PGP 9.5) antibody (1:500; Millipore, Billerica, MA), rabbit polyclonal anti- $\alpha$-SMA antibody (1:200; Santa Cruz Biotechnology Inc.), and anti-rabbit PECAM antibody (1:200; Santa Cruz Biotechnology Inc.). After the sections were rinsed with PBS, the following secondary antibodies were loaded: Alexa Fluor 594-coupled goat anti-rabbit IgG antibody (1:200; Invitrogen). Finally, nucleus staining was performed using DAPI (Merck). The stained sections were observed using a fluorescence microscope 
(BX51, Olympus Optical) and images were obtained by a CCD camera (DP70, Olympus Optical).

2.12. Capillary Number to Muscle Fiber Ratio. Capillary number to muscle fiber ratio was calculated as previously reported $[44,49]$ with minor modifications. In brief, the sections of soleus muscles fixed with PFA were used for immunostaining. The vascular capillaries were stained by Alexa Fluor 594 conjugate isolectin GS-IB4 (invitrogen) and counted under a fluorescence microscope (BX51, Olympus Optical), and images were obtained by a CCD camera (DP70, Olympus Optical). The muscle fibers were concomitantly counted to determine the capillary number to muscle fiber ratio. Five fields from each section were randomly selected for the capillary counts.

2.13. Measurement of Intraepidermal Nerve Fiber Densities (IENFDs). Nerve fibers stained with anti-PGP 9.5 antibody were counted as previously reported [51]. In brief, the number of nerve fibers was counted at the point of intersection with the basal membrane, regardless of branching within the dermis or epidermis. Six captured images from each section were randomly selected for IENFDs. IENFDs were derived and expressed as epidermal nerve fiber numbers per length of an epidermal basal membrane (fibers/mm).

2.14. Statistical Analysis. All of the group values were expressed as means $\pm \mathrm{SD}$. Statistical analyses were made by oneway ANOVA, with the Bonferroni correction for multiple comparisons. All analyses were performed by personnel unaware of the animal identities.

\section{Results}

3.1. Flk1 $\mathrm{I}^{+}$Cells Obtained from ES Cells Expressed Mesodermal and Angioblastic Markers. After culturing 4 days on gelatin, the shape of the ES cell colonies changed from spherical to planar and the population of cells expressing Flk1 was estimated at 10-20\% using FACS analysis (Figures 1(a) and 1(b)). Purification mediated by Flk1 antibody was validated, and Flk1 mRNA expression in Flk1 ${ }^{+}$cells was measured at almost 30 times higher than that in Flk1 negative $\left(\mathrm{Flk1}^{-}\right)$cells (Figure 1(c)). RT-PCR analyses showed both mesodermal and angioblast markers; that is, Brachyury, Flk1, Flt1, Tie1, Tie2, VE-cad, PU.1, SCL/Tal1, and Lmo2, were expressed in Flk1 ${ }^{+}$ cells purified employing MACS (Figure 1(d)).

3.2. $\mathrm{Flk1}^{+}$Angioblastic Cells Expressed Angiogenic and Neurotrophic Factors. RT-PCR analyses revealed that sorted angioblast-like cells induced from ES (hereafter referred to as $\mathrm{ES}-\mathrm{AB}$ ) expressed angiogenic and neurotrophic factors: VEGF-A, PDGF-A, FGF2, NGF, brain-derived neurotrophic factor (BDNF), glial cell line-derived neurotrophic factor (GDNF), Neurotrophin-3 (NT-3), and ciliary neurotrophic factor (CNTF) (Figure 2). Expression of FGF2, NGF, and GDNF was significantly increased in ES-ABs compared with $\mathrm{Flk1}^{-}$cells. It is widely known that Schwann cells provide mechanical protection and paracrine effects relying on the production of neurotrophic and angiogenic factors. Therefore, we evaluated the relative expression levels of these growth factors in ES-ABs compared with a mouse Schwann cell line, IMS32. Although the expressions of GDNF, NGF, FGF2, PDGF-A, and CNTF evidenced a significant decrease in ES-ABs compared with IMS32, the expressions of VEGFA and NT-3 in ES-ABs were comparable to those in IMS32 (Figure 2). Furthermore, the expression of BDNF significantly increased in ES-ABs compared to IMS32. In addition, we compared the relative expression levels of these growth factors between ES-ABs and mouse MSCs, which have been widely applied in ischemic diseases with an expectation of their paracrine effects. Although expression levels of GDNF and FGF2 in ES-ABs showed a significant decrease compared with those in PA6 cells, a cell line of mouse MSCs, there was no significant difference in levels of VEGF-A, NGF, BDNF, and CNTF expressions between ES-ABs and MSCs. Additionally, there were significant increases of NT-3 and PDGF-A expression levels in ES-Abs compared with PA6 cells.

\subsection{ES-ABs Purified with MACS Differentiated to Endothelial} Cells and Smooth Muscle Cells In Vitro. Following purification with MACS, the ES-ABs were cultured on gelatin for additional 4 days to assess their abilities to differentiate to endothelial cells and smooth muscle cells. After the culture, cells formed numerous colonies. The use of the immunocytochemistry method revealed that some colonies expressed an endothelial marker, PECAM, and the other colonies expressed a smooth muscle cell marker, $\alpha$-SMA (Figure 3).

3.4. Structured Tube Formation and "Cobblestone" Monolayer Were Constructed from ES-ABs. To elucidate whether ESABs themselves are enabled to form blood vessels, sorted ES-AB and Flk1 $1^{-}$cells were separately seeded on Matrigel. After culturing for 2 days on Matrigel, cells were visualized with isolectin IB4. Although endothelial cells stained with IB4 were rarely induced from Flk1 ${ }^{-}$cells, significantly heavy numbers of endothelial cells were induced from $\mathrm{Flk}^{+}$cells. In addition, a portion of these endothelial cells restructured into a vessel-like tube formation, and the remaining portion deployed into a cobblestone-like configuration (Figures 4(a) and $4(\mathrm{~b})$ ).

3.5. Body Weights, Blood Glucose Levels, and HbAlc. At 12 weeks, diabetic mice showed severe hyperglycemia (random blood glucose levels: $P=0.0003$. HbAlc: $P<0.0001$ ) and significantly decreased body weight gain $(P=0.003)$ (Table 2 ). After the transplantation of ES-ABs, there was no significant change between transplanted and nontransplanted mice (Table 2).

3.6. Some Blood Vessel Walls and Capillaries Were Constructed with Transplanted Cells. To detect the distribution of transplanted cells, several mice were injected with GFP-expressing ES-ABs. To determine the existence of teratomas, four weeks after the transplantation, the muscles, brains, hearts, lungs, and livers of these mice were collected and sectioned. GFP positive $\left(\mathrm{GFP}^{+}\right)$cells were nonexistent except in muscles of 

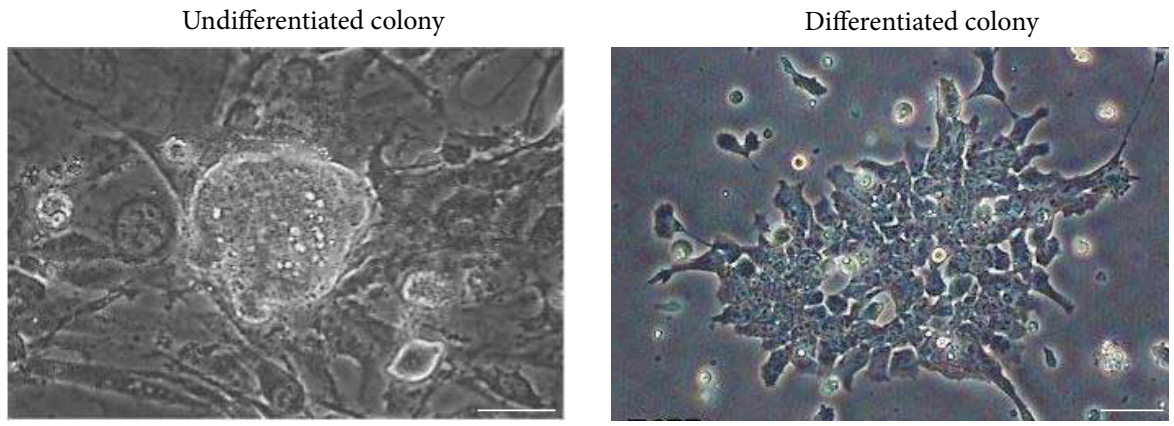

(a)
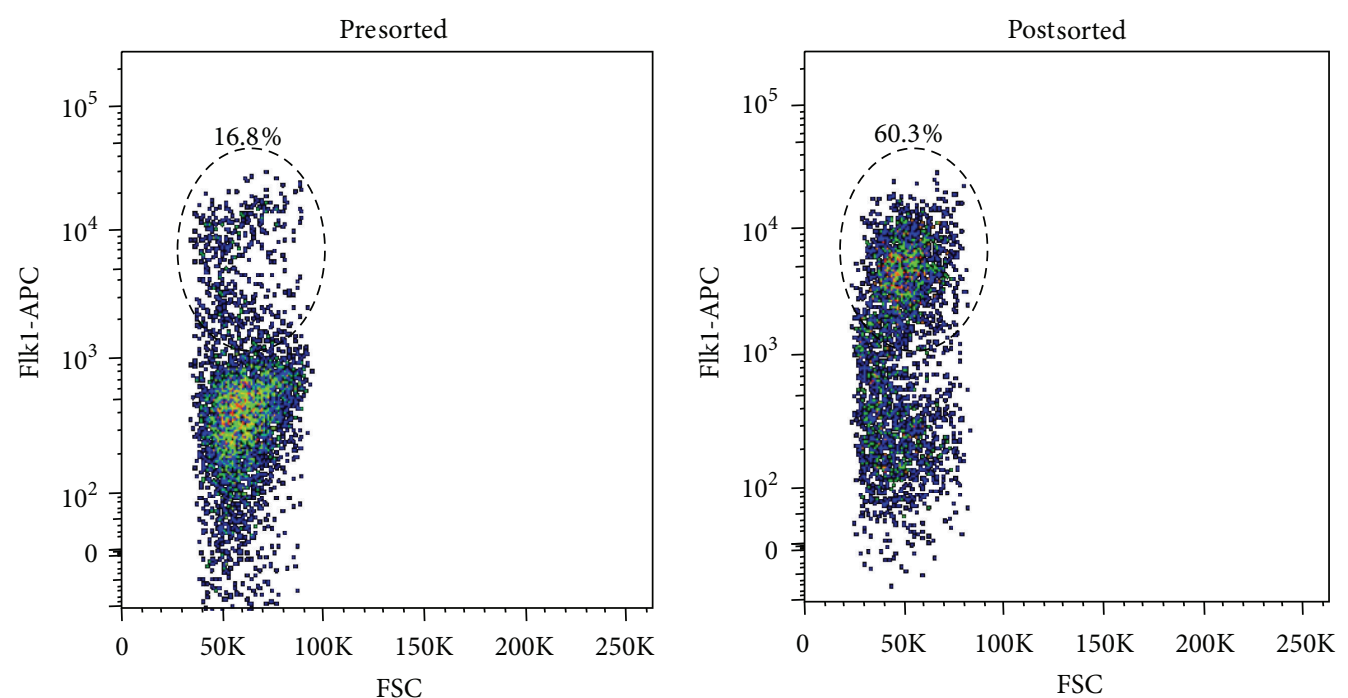

(b)

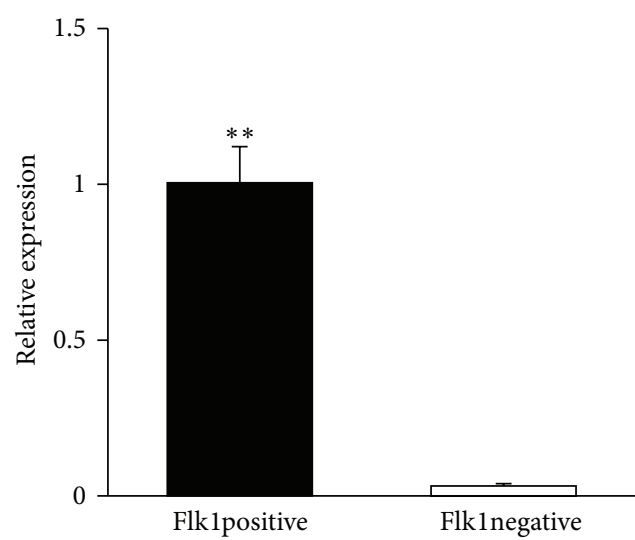

(c)

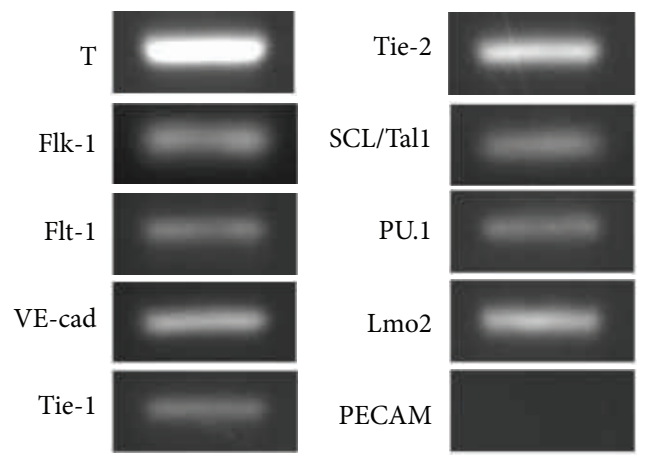

(d)

FIGURE 1: Differentiation and purification of angioblast-like cells from mouse ES cells. (a) Spherical colonies of ES cells (left) were flatly outspread (right) after 4 days of culture on gelatin. Bar: $30 \mu \mathrm{m}$. (b) Fluorescence-activated cell sorting analyses showed that a population of cells expressing Flk1 was estimated at 10-20\% (left) and came up to 55-63\% by magnet associated cell separation (right). (c) Reversetranscription PCR analyses showed that Flk1 mRNA expression in population selected as Flk1 positive cell was almost 30 times higher than that in population selected as Flk1 negative cell $(P<0.001)$. (d) Reverse-transcribed PCR analyses showed both mesoderm and angioblast markers, that is, Brachyury (T), Flk1, Flt1, Tie1, Tie2, VE-cad, PU.1, SCL/Tal1, and Lmo2, which were expressed in Flk1 positive cells. On the other hand, PECAM, which is considered as a marker of relatively differentiated endothelial cell, was not detected in Flk1 positive cells after the 4 days of differentiation. 

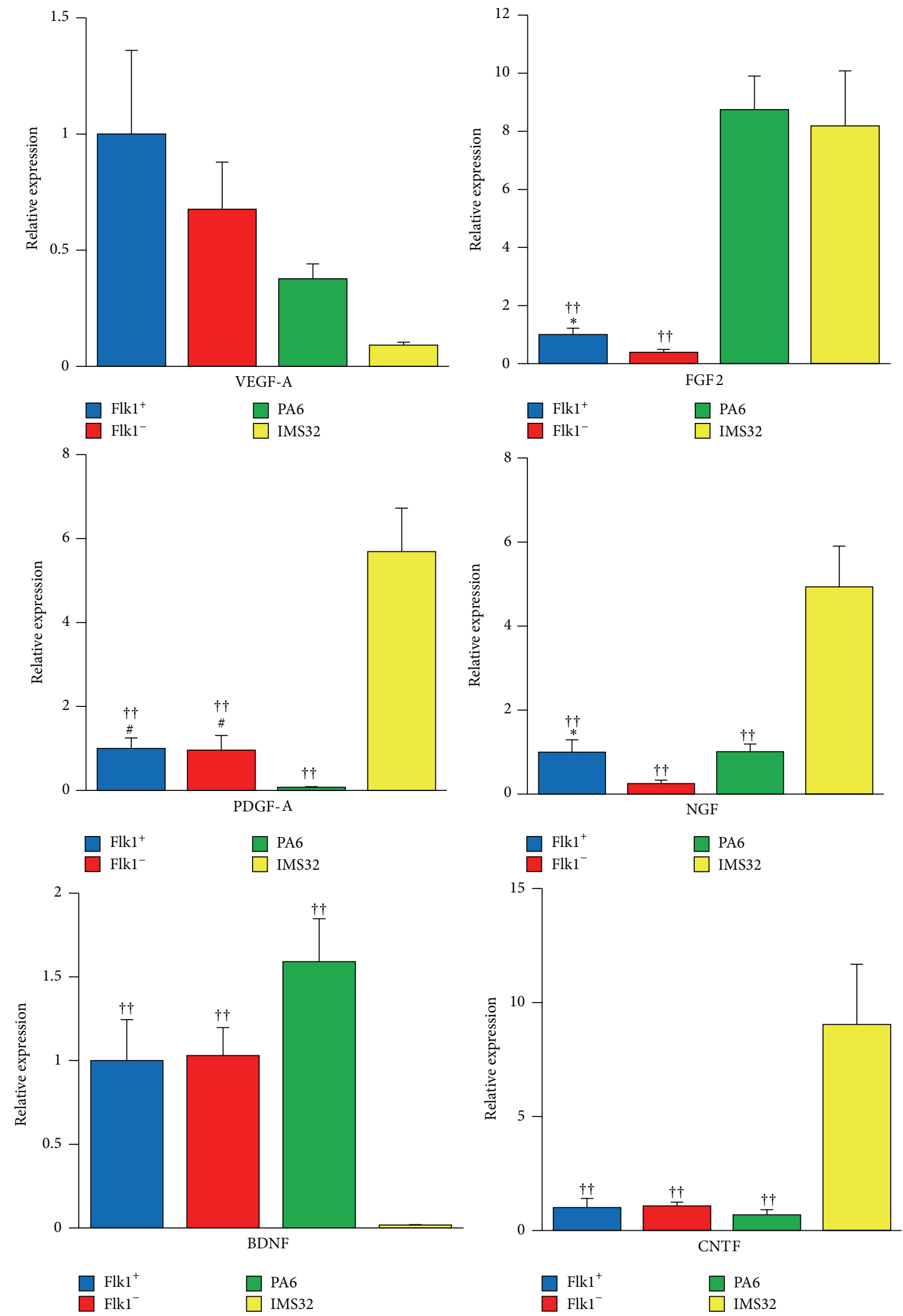

Figure 2: Continued. 

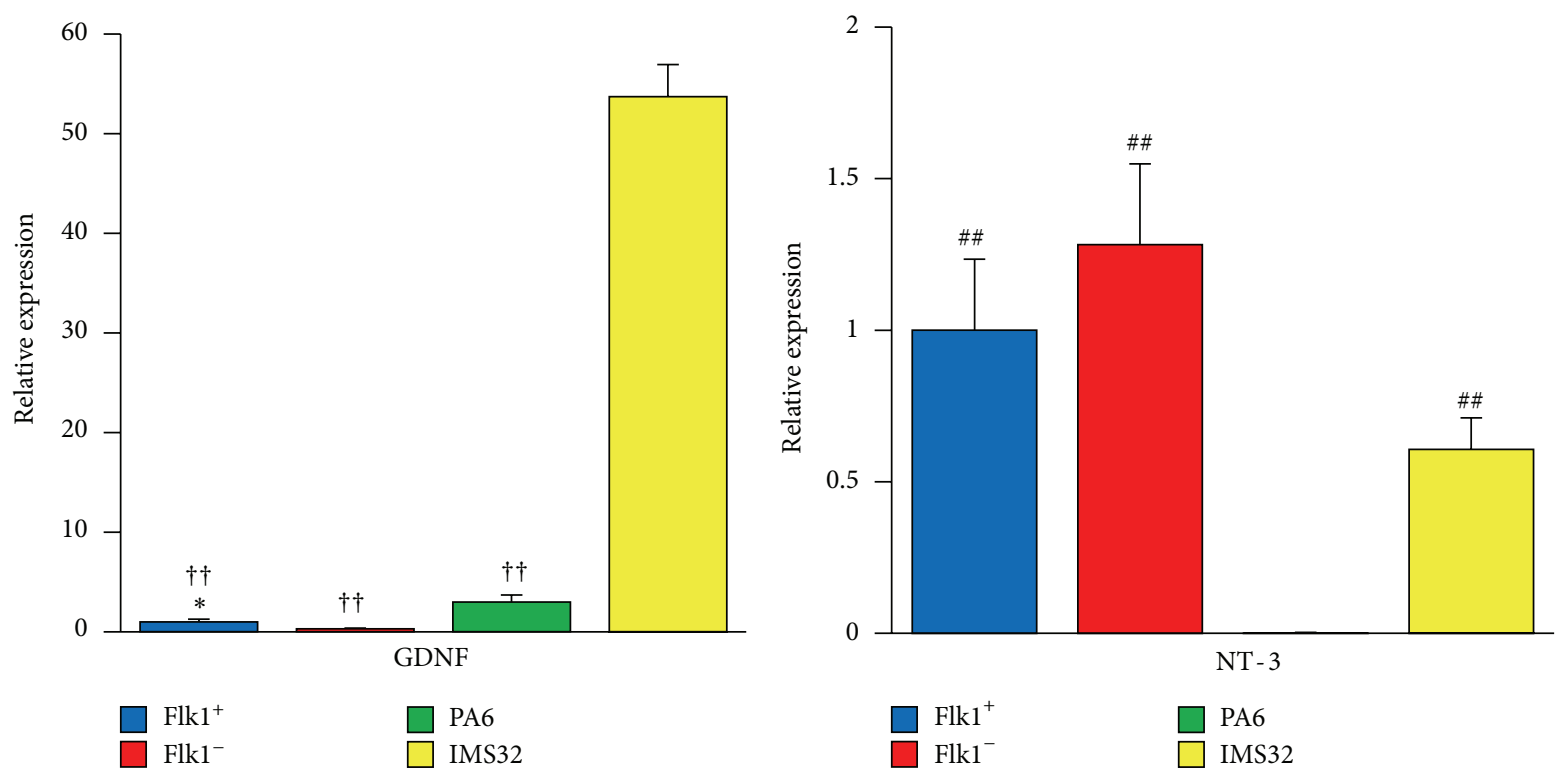

FIGURE 2: Transcript levels of angiogenic and neurotrophic factors in angioblast-like cells induced from ES cells (ES-ABs). Sorted ES-ABs expressed angiogenic and neurotrophic factors: VEGF-A, PDGF-A, FGF2, NGF, brain-derived neurotrophic factor (BDNF), glial cell linederived neurotrophic factor (GDNF), Neurotrophin-3 (NT-3), and ciliary neurotrophic factor (CNTF). Each expression level of the factors compared Flk1 positive cells with Flk1 negative cells, PA6 cells, and IMS32 cells. PA6: a cell line of mouse mesenchymal stem cell and IMS32: a cell line of immortalized mouse Schwann cell. Flk1 ${ }^{+}$: Flk1 positive cells and Flk1 ${ }^{-}$: Flk1 negative cells. ${ }^{*} P<0.05$ versus Flk1 ${ }^{-}$cells, ${ }^{\# \#} P<0.005$ versus PA6 cells, and ${ }^{\dagger \dagger} P<0.005$ versus IMS32 cells.

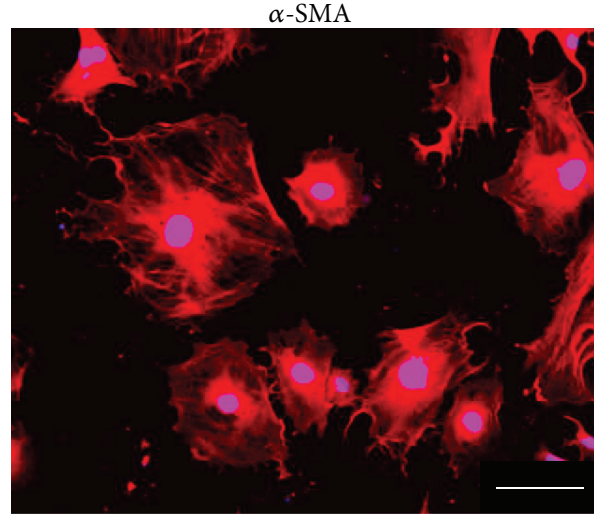

(a)

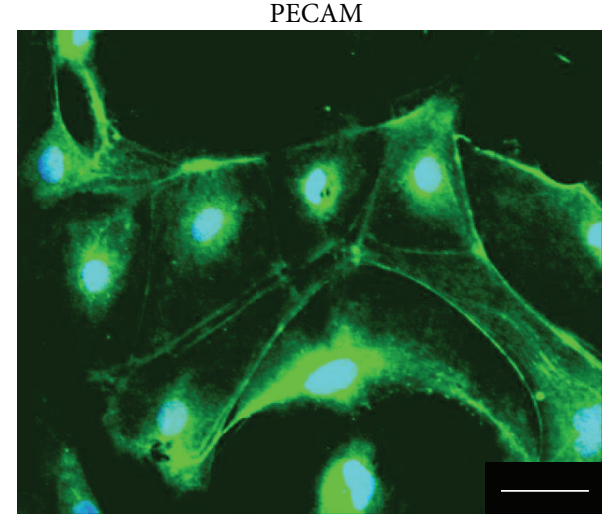

(b)

FIGURE 3: In vitro differentiation potential of angioblast-like cells induced from ES cells (ES-ABs). After a 4-day culture on gelatin, ES-ABs formed many colonies. Immunocytochemistry, a smooth muscle cell marker, $\alpha$-SMA, was detected at some colonies (a), and an endothelial marker, PECAM, was at the other colonies (b). Red: $\alpha$-SMA and green: PECAM. Bar: $100 \mu \mathrm{m}$.

the transplanted hindlimbs. $\mathrm{GFP}^{+}$cells resided in the gaps between muscle fibers and some $\mathrm{GFP}^{+}$cells were observed in the walls of blood vessels interspersed with GFP negative cells (Figure 5). Some of the $\mathrm{GFP}^{+}$cells found within the construct of the vessel walls were smooth muscle cells expressing $\alpha$ SMA (Figure 5(a)), while the others were endothelial cells expressing PECAM (Figure 5(b)).

3.7. Capillary Number to Muscle Fiber Ratio. The vasculatures were visualized by Alexa594-conjugated isolectin IB4, a marker for endothelial cells (Figure 6(a)). Quantitative analyses revealed that the capillary number to muscle fiber ratios in the saline-injected diabetic mice were significantly reduced compared with those in normal mice $(P=0.0004)$ (Figure 6(b)). Transplantation of ES-ABs significantly augmented the ratio in ES-AB transplanted limbs (ES-AB ${ }^{\mathrm{ipsi}}$ ) compared with the ratio in the saline-injected side limbs $\left(\mathrm{ES}-\mathrm{AB}^{\mathrm{contra}}\right)$ in diabetic mice $(P=0.0276)$ (Figure 6(b)). Transplantation of ES-ABs into normal mice showed no significant differences $(P=0.9609)$ (Figure 6(b)). 

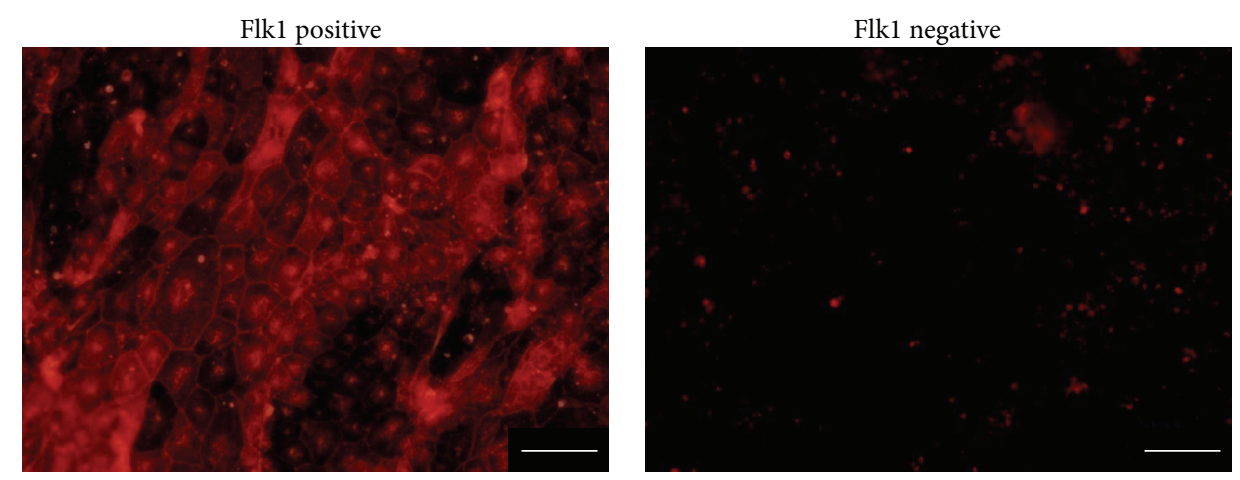

(a)
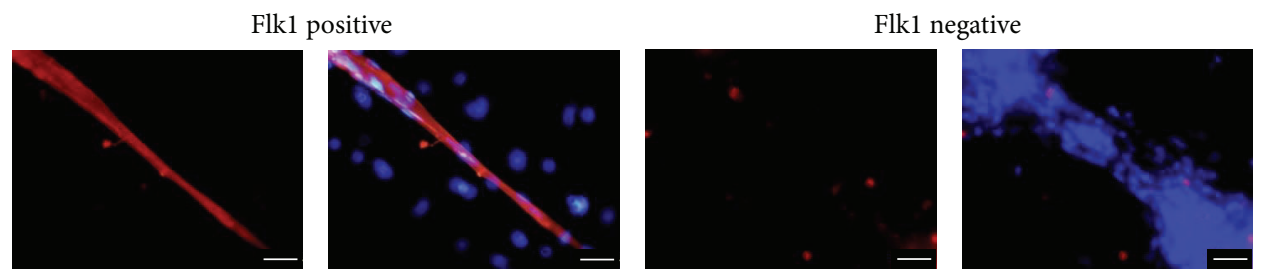

(b)

FIgURE 4: Tube forming assay of angioblast-like cells induced from ES cells (ES-ABs) on Matrigel. To elucidate whether ES-ABs themselves are enabled to form blood vessels, sorted ES-ABs and Flk1 negative cells were, respectively, seeded on Matrigel. Two days later, cells were visualized with isolectin IB4, a stain of endothelial cell. (a) Although endothelial cells stained with IB4 were rarely induced from Flk1 negative cells (right), heavy numbers of endothelial cells were induced from ES-ABs and deployed cobblestone-like pattern (left). Bar: $100 \mu \mathrm{m}$. Red: isolectin IB4. (b) In ES-AB culture, a part of cells stained with IB4 structured vessel like tube formation (left 2 images). On the other hand, cells forming a line were not stained with IB4 in culture of Flk1 negative cells (right 2 images). Bar: $100 \mu \mathrm{m}$. Red: isolectin IB4 and blue: DAPI.

TABLE 2: Body weight, blood glucose, and HbAlc levels.

\begin{tabular}{|c|c|c|c|c|c|c|}
\hline & \multicolumn{3}{|c|}{ Normal mice } & \multicolumn{3}{|c|}{ Diabetic mice } \\
\hline & \multirow{2}{*}{ Before transplantation } & \multicolumn{2}{|c|}{ After transplantation } & \multirow{2}{*}{ Before transplantation } & \multicolumn{2}{|c|}{ After transplantation } \\
\hline & & Saline & ES-AB & & Saline & ES-AB \\
\hline HbAlc (\%) & $4.0 \pm 0.1$ & $4.1 \pm 0.2$ & $4.1 \pm 0.2$ & $7.3 \pm 1.4^{* *}$ & $7.7 \pm 2.1^{\# \#}$ & $7.7 \pm 2.5^{\# \#}$ \\
\hline Blood glucose (mmol/L) & $9.1 \pm 1.6$ & $9.2 \pm 1.6$ & $9.1 \pm 1.6$ & $23.1 \pm 2.8^{* *}$ & $25.8 \pm 8.0^{\# \#}$ & $24.2 \pm 9.0^{\# \#}$ \\
\hline Body weight $(\mathrm{g})$ & $30.6 \pm 2.7$ & $31.3 \pm 3.0$ & $31.9 \pm 3.7$ & $26.1 \pm 3.1^{* *}$ & $25.3 \pm 3.2^{\# \#}$ & $27.6 \pm 1.6^{\# \#}$ \\
\hline
\end{tabular}

Results are means \pm SD. ES-AB: mice transplanted angioblast-like cells induced from embryonic stem cell. ${ }^{* *} P<0.005$ versus pretreatment normal mice. ${ }^{\# \#} P<0.005$ versus posttreatment normal mice.

3.8. Transplantation of ES-ABs Increased Blood Flow in the Sciatic Nerve and Plantar Skin. After 12 weeks of diabetes, the blood flow in both the sciatic nerve and plantar skin in diabetic mice decreased significantly compared with that in normal mice (sciatic nerve: $P=0.0431$; plantar skin: $P=$ 0.0359 ), and the decrease was ameliorated by transplantation of ES-ABs (sciatic nerve: $P=0.0003$ represents DM-S versus DM-ES-AB ${ }^{\text {ipsi }}$; plantar skin: $P=0.0211$ represents DM-S versus $\left.\mathrm{DM}-\mathrm{ES}-\mathrm{AB}^{\mathrm{ipsi}}\right)$. However, administration of ES-ABs did not alter the blood flow in normal mice (sciatic nerve: $P=0.9525$ represents $\mathrm{N}-\mathrm{S}$ versus $\mathrm{N}-\mathrm{ES}-\mathrm{AB}^{\mathrm{ipsi}}$; plantar skin: $P=0.2523$ represents $\mathrm{N}-\mathrm{S}$ versus ES-AB ${ }^{\text {ipsi }}$ ) (Figure 7).

3.9. Reduced Sensory Perception in Diabetic Mice Was Ameliorated by ES-AB Transplantation. After 12 weeks of diabetes, CPTs at 5,250 , and $2000 \mathrm{~Hz}$ had significantly increased compared with those in normal mice $(5 \mathrm{~Hz}: P=0.015 ; 250 \mathrm{~Hz}$ :
$P=0.019 ; 2000 \mathrm{~Hz}: P=0.028)$, representing hypoalgesia in diabetic mice. The fourth week after the transplantation of ES-ABs, these deficits in sensation had significantly improved in diabetic mice compared with saline-treated diabetic controls (5 Hz: $P=0.071$ represents DM-S versus DM-ES-AB ${ }^{\text {ipsi; }}$; $250 \mathrm{~Hz}: P=0.0018$ represents $\mathrm{DM}-\mathrm{S}$ versus $\mathrm{DM}-\mathrm{ES}-\mathrm{AB}^{\mathrm{ipsi}}$; $2000 \mathrm{~Hz}: P<0.0001$ represents DM-S versus DM-ES-AB ${ }^{\mathrm{ipsi}}$ ). The transplantation of ES-ABs into normal mice did not induce significant changes in CPTs $(5 \mathrm{~Hz}: P=0.934$ represents N-S versus N-ES-AB ${ }^{\text {ipsi }}$; $250 \mathrm{~Hz}: P=0.212$ represents $\mathrm{N}-\mathrm{S}$ versus $\mathrm{N}-\mathrm{ES}-\mathrm{AB}^{\mathrm{ipsi}}$; $2000 \mathrm{~Hz}$ : $P=0.260$ represents $\mathrm{N}-\mathrm{S}$ versus $\mathrm{N}-\mathrm{ES}-\mathrm{AB}^{\mathrm{ipsi}}$ ) (Figure 8).

3.10. ES-ABs Improved Delayed NCVs in Diabetic Mice. MNCV and SNCV of diabetic mice were significantly delayed compared with those of normal mice (Figure 9). The delay in MNCV and SNCV was significantly restored by ES-AB 
GFP

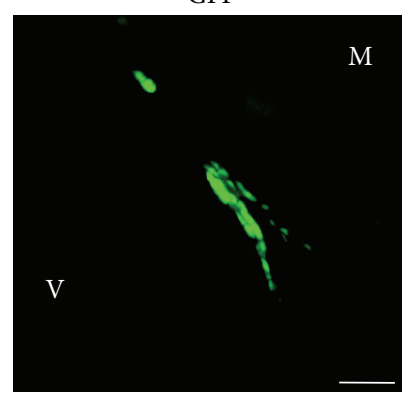

GFP

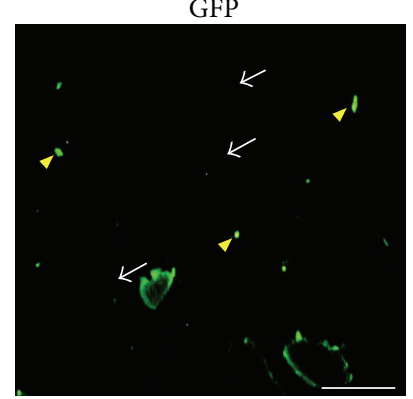

$\alpha$-SMA

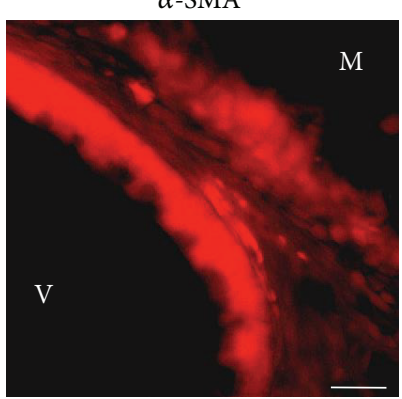

(a)

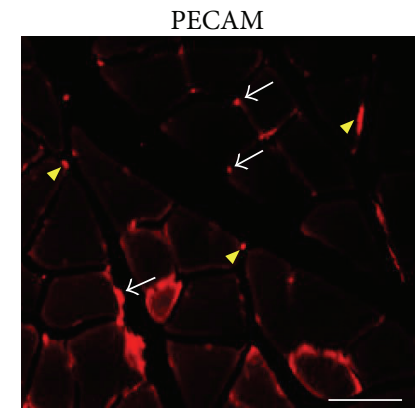

(b)

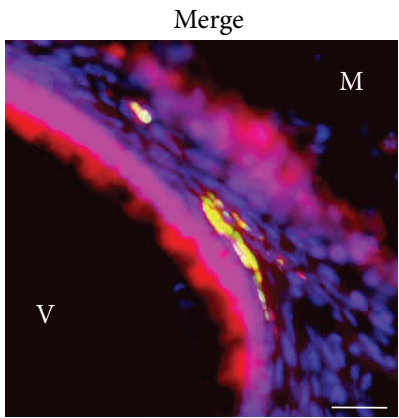

Merge

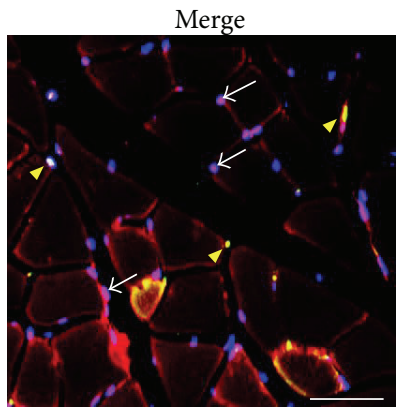

FIGURE 5: The transplanted angioblast-like cells induced from ES cells (ES-ABs) constructed blood vessel walls and capillaries. Immunohistochemical staining revealed that transplanted GFP-expressing ES-ABs were still engrafted 4 weeks after transplantation. (a) The engrafted cells distributed in vessel wall between hindlimb muscle fibers and coexpressed $\alpha$-SMA. Green: GFP and red: $\alpha$-SMA. M: muscle and V: lumen of a blood vessel. Bar: $20 \mu \mathrm{m}$. (b) Some of GFP positive cells resided in gaps between soleus muscle fibers and coexpressed PECAM. Green: GFP and red: PECAM. White arrows: GFP negative capillaries and yellow arrowheads: GFP positive capillaries. Bar: $20 \mu \mathrm{m}$.
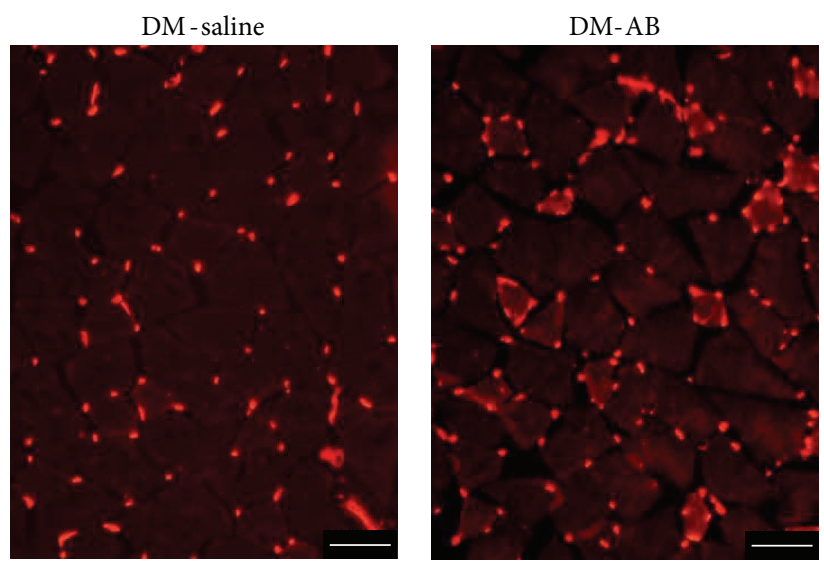

(a)

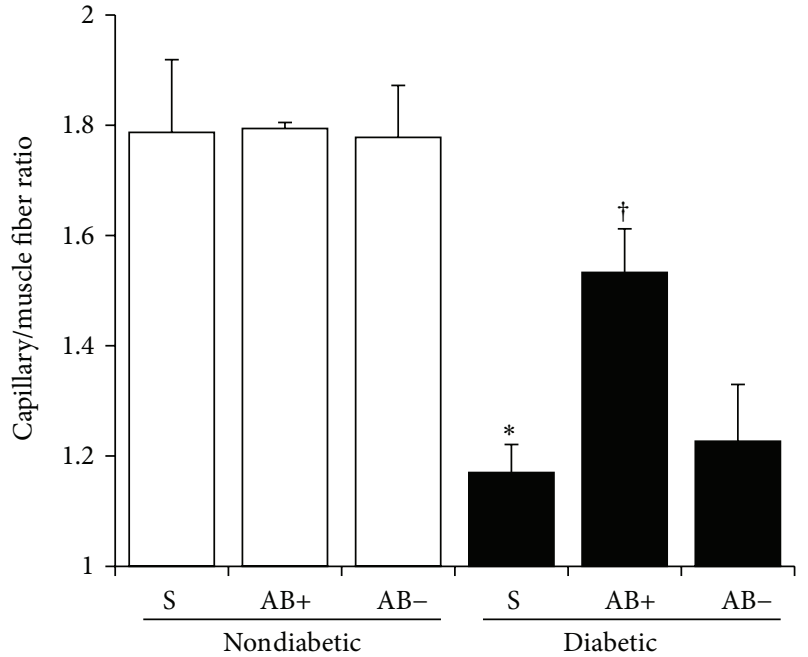

(b)

Figure 6: Capillary number to muscle fiber ratios in soleus muscles. (a) The vasculatures were visualized by Alexa594-conjugated isolectin IB4 in soleus muscles. More capillaries existed in soleus muscle of transplanted diabetic mice (right) compared to those of nontransplanted control diabetic mice (left). Red: isolectin IB4. Bar: $50 \mu \mathrm{m}$. DM-saline: saline-injected limb in diabetic mice and DM-AB: limbs transplanted angioblast-like cell derived from ES cells in diabetic mice. (b) Quantitative analyses revealed that the capillary number to muscle fiber ratios in the saline-injected sides of diabetic mice were significantly reduced compared with those of normal mice (N). Transplantation of angioblastlike cell derived from ES cells (ES-ABs) significantly augmented the ratios in transplanted limbs compared with those in saline-injected side limbs in diabetic mice (DM). Transplantation of ES-ABs into normal mice showed no significant differences. S: saline treated limbs, AB+: limbs transplanted ES-ABs, and $\mathrm{AB}-$ : contralateral limbs transplanted ES-ABs. Results are means $\pm \mathrm{SD}$. ${ }^{*} P<0.05$ versus $\mathrm{S}$ in $\mathrm{N}(\mathrm{N}-\mathrm{S})$ and ${ }^{\dagger} P<0.05$ versus $\mathrm{S}$ in DM (DM-S). $N=4$ in N-S and $n=3$ in DM-S $(P=0.0004) . N=3$ of AB+in DM and $n=5$ of AB-in DM $(P=0.0276$ represents $\mathrm{DM}-\mathrm{S}$ versus $\mathrm{AB}+$ in $\mathrm{DM}) \cdot \mathrm{N}=4$ of $\mathrm{AB}+$ in $\mathrm{N}$ and $n=4$ of $\mathrm{AB}-$ in $\mathrm{N}(P=0.9609$ represents $\mathrm{N}-\mathrm{S}$ versus $\mathrm{AB}+$ in $\mathrm{N})$. 


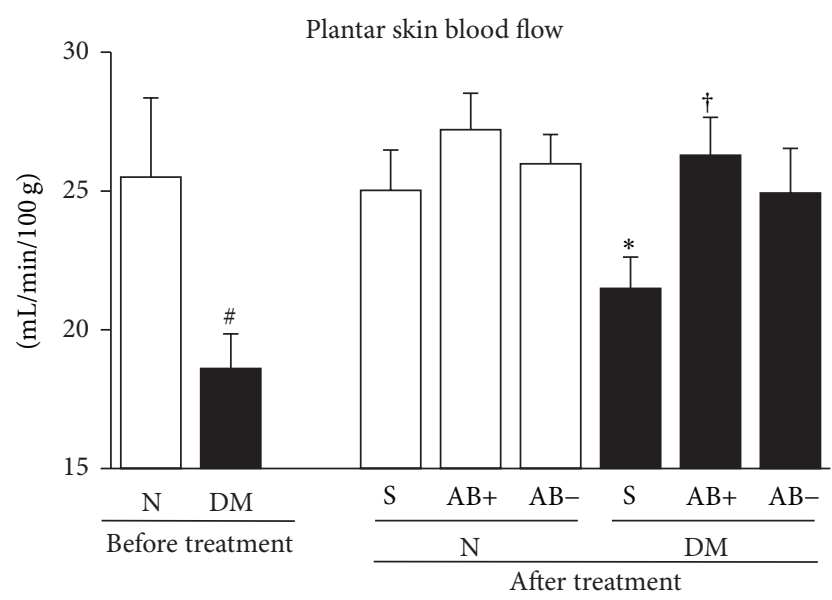

(a)

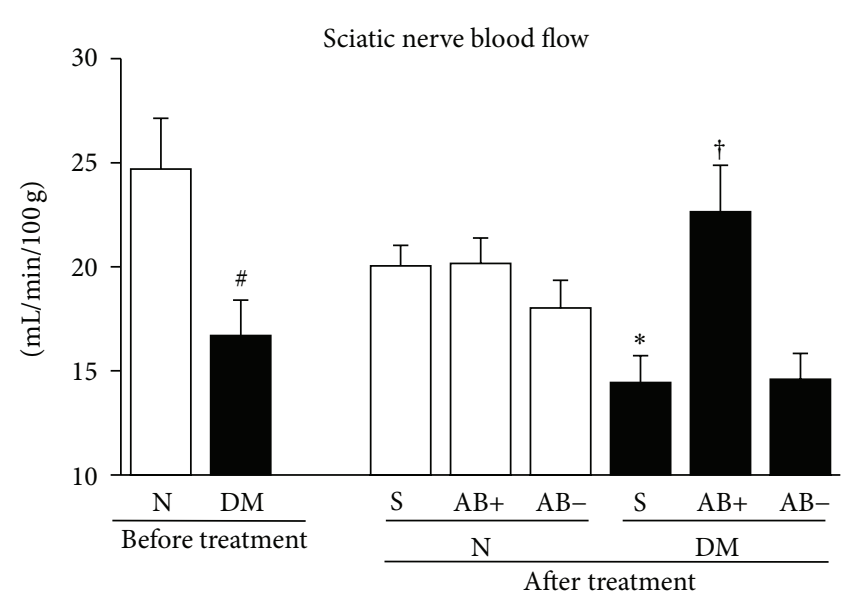

(b)

FIGURE 7: Blood flow of sciatic nerves and plantar skins were ameliorated by transplantation of angioblast-like cell derived from ES cells (ES-ABs). At a time point of 12 weeks of diabetes (before treatment), blood flows of plantar skins (a) and sciatic nerves (b) in diabetic mice significantly decreased compared with those in normal mice, and, 4 weeks after transplantation (after treatment), the decreases were ameliorated in transplanted limbs of diabetic mice. However, administration of ES-ABs did not alter blood flow in those of normal mice. $\mathrm{N}$ : normal mice limbs, DM: diabetic mice limbs, S: saline-injected limbs, AB+: limbs transplanted ES-ABs, and AB-: contralateral limbs transplanted ES-ABs. Results are means \pm SD. ${ }^{\#} P<0.05$ versus pretreatment $\mathrm{N} .{ }^{*} P<0.05$ versus posttreatment $\mathrm{S}$-treated $\mathrm{N}$, ${ }^{\dagger} P<0.05$ versus posttreatment S-treated DM. $n=4-6$ in each pretreatment group and $n=7-10$ in each posttreatment group.

transplantation (MNCV: $P=0.0289$ represents DM-S versus DM-ES-AB ${ }^{\text {ipsi }}$; SNCV: $P=0.0201$ represents DM-S versus DM-ES-AB ${ }^{\text {ipsi }}$ ) (Figure 9). However, administration of ESABs did not alter NCVs in normal mice (MNCV: $P=0.7604$ represents N-S versus ES-AB ${ }^{\text {ipsi }}$; SNCV: $P=0.6016$ represents $\mathrm{N}-\mathrm{S}$ versus N-ES-AB ${ }^{\text {ipsi }}$ ) (Figure 9).

3.11. Nerve Fibers in the Epidermis Were Preserved by ES-ABs. Utilization of fluorescent imaging showed that nerve fibers in the plantar skin were evidenced in both the epidermis and the dermis (Figure 10(a)). After 12 weeks of diabetes, IENFDs decreased in diabetic mice $(P=0.0011)$ (Figure $10(\mathrm{~b}))$. This decrease was significantly ameliorated by ES-ABs $(P=0.0355$ represent DM-S versus DM-ES-AB $\left.{ }^{\mathrm{ipsi}}\right)$. Administration of ES-ABs did not change IENFDs in normal mice $(P=0.3212$ represents N-S versus N-ES-AB ${ }^{\text {ipsi }}$ ) (Figure 10(b)).

\section{Discussion}

The present study demonstrated that angioblast-like cells could be obtained from mouse ES cells and the transplantation of the angioblast-like cells, ES-AB, improved several physiological impairments in DPN: hypoalgesia, delayed NCVs, and reduced blood flow in sciatic nerves and plantar skin. The immunohistological assessment revealed that the capillary number to muscle fiber ratios increased in skeletal muscles of the transplanted hindlimbs, and intraepidermal nerve fiber densities were also ameliorated in the transplanted plantar skin samples. Four weeks after the transplantation, transplanted cells maintained their viabilities and differentiated to endothelial cells and smooth muscle cells around the injected sites. Moreover, several transplanted cells constructed chimeric blood vessels with recipient cells.

One of the most significant characteristics of the current transplantation therapy was the utilization of the heterogeneous graft cells which were at the early stage of differentiation of the pluripotent stem cells. We expected some advantages of a utilization of cells at the early stage, for example, a multipotent differentiation ability, a high migratory capacity, high adaptability to microenvironments of host tissues, a high proliferation ability, and a capacity to produce various growth factors. In previous studies, $\mathrm{Flk}^{+}$cells derived from mouse pluripotent stem cells have been shown to differentiate into a number of cell types including endothelial cells, smooth muscle cells, and cardiomyocytes in vitro $[47,52]$. In the current study, it was demonstrated that the adhesive Flk1 ${ }^{+}$cells derived from mouse ES cells had a multipotent differentiation ability into endothelial cells and smooth muscle cells, similar to the previous studies and expressed several angioblast markers including Flt1, Tie2, and VE-cad. Furthermore, transplanted cells engrafted themselves in gaps between muscle fibers around transplanted sites and were incorporated into the tissue structures of recipient animals. These results indicate that some of the therapeutic effects obtained in this study were mediated through the differentiation of ES-ABs.

Additionally, we demonstrated that ES-ABs secreted a wide array of growth factors, such as, FGF2, VEGF, PDGF, NGF, BDNF, GDNF, NT-3, and CNTF. In previous studies, MSC transplantation has been performed in the field of ischemic diseases, and it has been suggested that its plausible effects would be mediated largely through paracrine actions of locally released arteriogenic cytokines including FGF2 and 


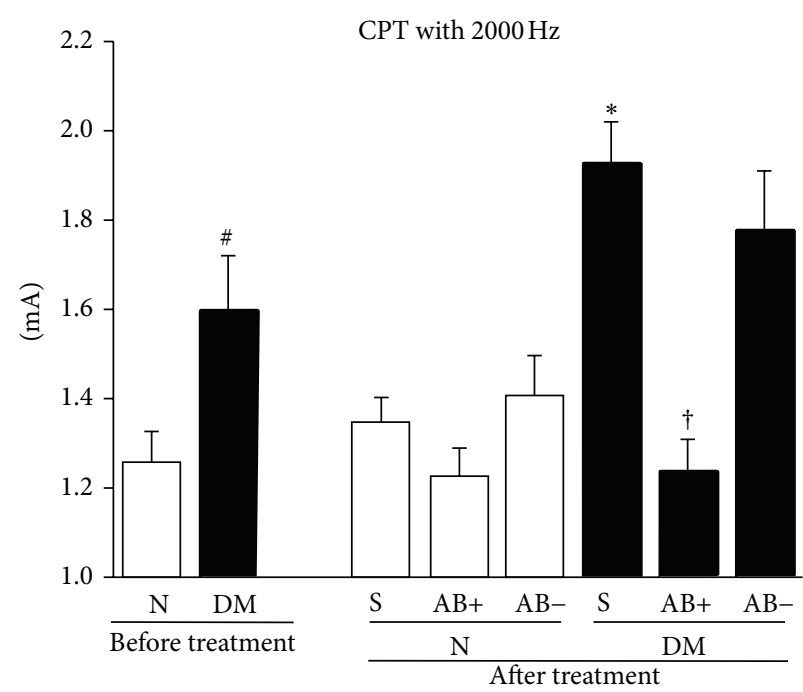

(a)

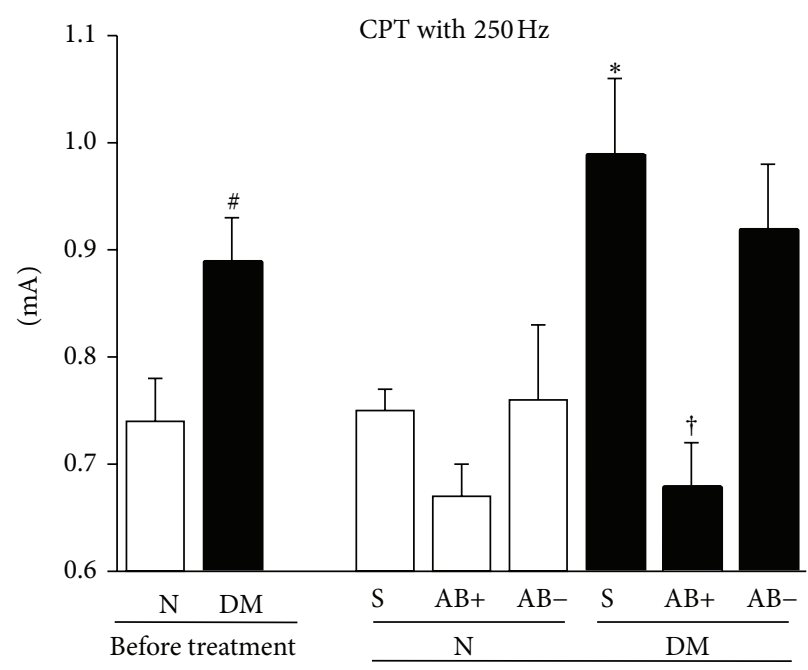

(b)

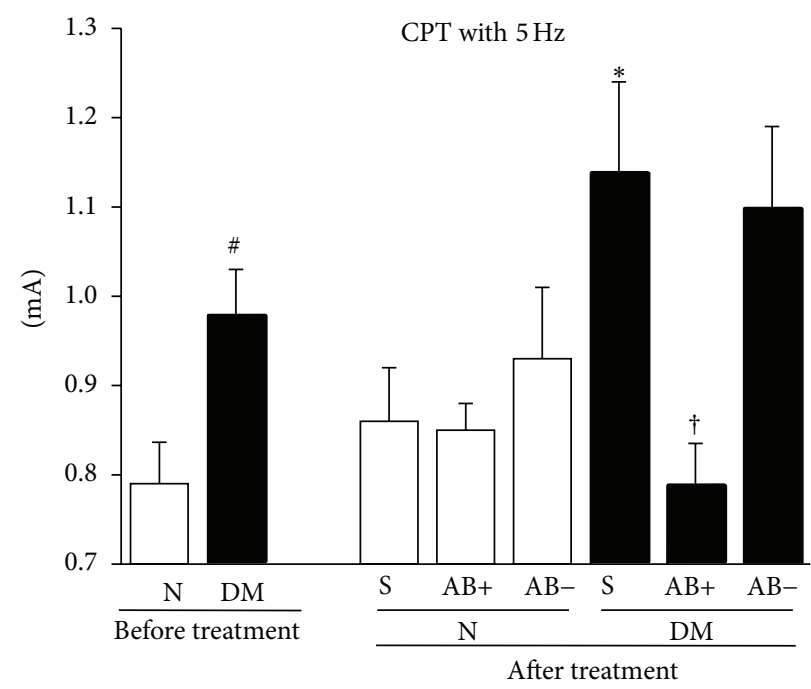

(c)

FIGURE 8: Impaired sensory perceptions in diabetic mice were ameliorated by angioblast-like cells induced from ES cells (ES-ABs) transplantation. Stimuli with frequencies of $5 \mathrm{~Hz}$ (a), $250 \mathrm{~Hz}$ (b), and $2000 \mathrm{~Hz}$ (c) evoked excitations of C-fiber, A $\delta$-fiber, and $\mathrm{A} \beta$-fiber, respectively. Before cell transplantation, CPTs with all kinds of stimuli in diabetic mice had significantly increased compared with those in normal mice, representing hypoalgesia in diabetic mice. Four weeks after the transplantation of ES-ABs, these deficits in sensation were significantly improved in diabetic mice compared with saline-treated diabetic controls. The transplantation of ES-ABs into normal mice did not induce significant changes in CPTs. N: normal mice limbs, DM: diabetic mice limbs, S: saline-injected limbs, AB+: limbs transplanted ES-ABs, and AB-: contralateral limbs transplanted ES-ABs. Results are means \pm SD. ${ }^{\#} P<0.05$ versus pretreatment $\mathrm{N},{ }^{*} P<0.05$ versus posttreatment S-treated $\mathrm{N}$, and ${ }^{\dagger} P<0.05$ versus posttreatment S-treated DM. $n=8-10$ in each nondiabetic group and $n=7-9$ in each diabetic group.

VEGF [53-55]. Furthermore, FGF2 and VEGF have been reported to have neurosupportive effects $[56,57]$. In our study, FGF2, VEGF, and PDGF were expressed in ES-ABs and, in particular, PDGF expression of ES-ABs was significantly higher than that of MSCs. In addition to these conventional angiogenic factors, neurotrophic factors, such as NGF, BDNF, GDNF, NT-3, and CNTF were expressed in ES-ABs. In the peripheral nervous system, these neurotrophic factors are predominantly secreted by Schwann cells. Although NGF and GDNF expressions in ES-ABs were significantly lower than those in Schwann cells, NT-3 and BDNF expressions in ES-ABs were favorably compared with those in Schwann cells. These observations suggest that the interventional effects of ES-AB transplantation on DPN demonstrated in this study would be partially achieved by the paracrine actions of growth factors, and these factors would work as 


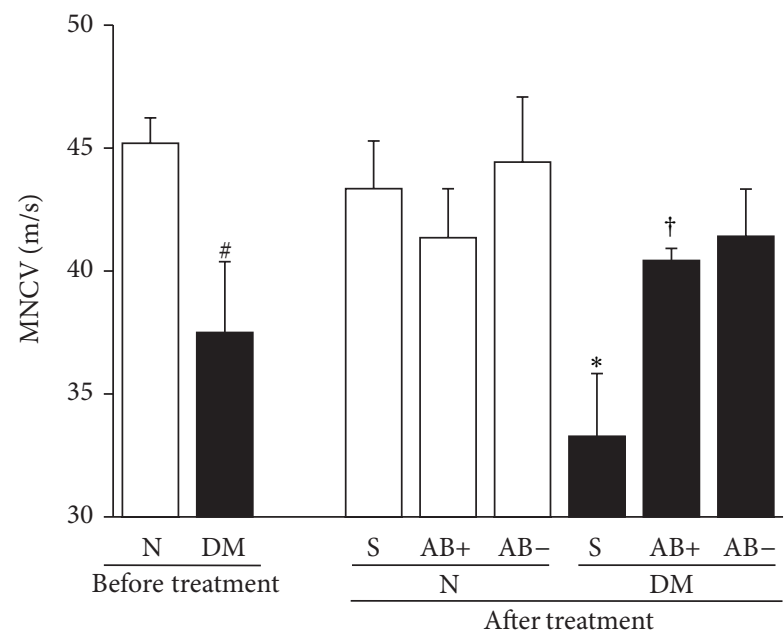

(a)

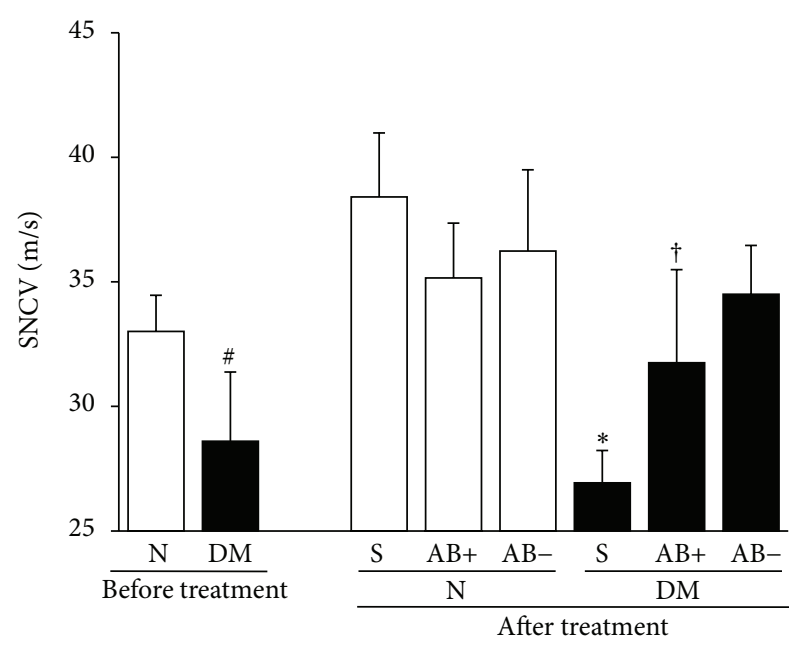

(b)

FIGURE 9: Transplantation of angioblast-like cells induced from ES cells (ES-ABs) improved delayed nerve conduction velocities (NCVs) in diabetic mice. Motor nerve conduction velocity (MNCV) (a) and sensory nerve conduction velocity (SNCV) (b) of diabetic mice were significantly delayed compared with those of normal mice after 12 weeks duration of diabetes. The delays in MNCV and SNCV were significantly restored by ES-ABs transplantation. However, administrations of ES-ABs did not alter NCVs in normal mice. N: normal mice limbs, DM: diabetic mice limbs, S: saline-injected limbs, AB+: limbs transplanted ES-ABs, and AB-: contralateral limbs transplanted ES-ABs. Results are means $\pm \mathrm{SD} .{ }^{*} P<0.05$ versus pretreatment $\mathrm{N},{ }^{*} P<0.05$ versus posttreatment $\mathrm{S}$-treated $\mathrm{N}$, and ${ }^{\dagger} P<0.05$ versus posttreatment S-treated DM. $n=6$ in each pretreatment group and $n=7-10$ in each posttreatment group.

both angiogenic and neurotrophic factors. However, further studies to elucidate which growth factor is relevant to the paracrine action should be considered.

Our study revealed that the capillary number to muscle fiber ratios in hindlimb skeletal muscles were significantly lower in diabetic mice than in normal mice, which is consistent with human studies [58], and the ES-AB transplantation might restore the decrease through induction and construction of neovascularization. The level of therapeutic vasculogenesis prompted by the ES-ABs transplantation was similar to that prompted by EPC transplantation, as we previously reported [44], and the differentiation and incorporation of ES-ABs to vessels were consistent with this report. However, it remains unknown why ES-AB transplantation did not have any effect on normal mice. It can be speculated that diabetic conditions such as hyperglycemia and impaired local microcirculation might cause or require the transplanted ES-ABs to more strongly produce growth factors and promote vasculogenesis. Further studies are in progress in our laboratory.

The impairment of nerve blood flow (NBF) is one of the major pathogenic factors in the development of DPN. Although there are some disagreements as to whether reduced NBF can account for diabetic neuropathy $[59,60]$, this notion is clinically and experimentally supported by many other studies, which reported that the amelioration of NBF by various treatments improved impaired nerve functions [61-63]. The beneficial effects of ES-AB transplantation on NCVs and NBFs in this study could be comparable to those of the therapeutic modalities reported previously. Reduced capillary number to muscle fiber ratios and blood flows of plantar skin in diabetic mice were ameliorated by transplantation of ES-ABs. Therefore, these ameliorations of
NCVs and NBFs may be due in part to vasculogenesis rendered by ES-ABs and, as mentioned above, paracrine effects of angiogenetic and neurotrophic factors produced by ES-ABs. However, well-conceived studies aiming to clarify molecular mechanisms of ES-Abs on each cell type in vascular and nervous systems should be performed in the future. Furthermore, it should be also considered to determine the duration of the beneficial effects using a lengthened intervention by repetitive transplantations.

In the present study, we evaluated sensory nerve functions using the Neurometer CPT/LAB. The Neurometer is a device that measures, selectively, the CPTs in three classes of afferent fibers by applying transcutaneous sine-wave electric stimuli to the skin at three frequencies of 2000, 250, and $5 \mathrm{~Hz}$ via surface electrodes at a current intensity in the range of $0.01-9.9 \mathrm{~mA}$. The pulses at 2000, 250, and $5 \mathrm{~Hz}$ mainly stimulate large myelinated $(\mathrm{A} \beta-)$, small myelinated $(\mathrm{A} \delta$-), and small unmyelinated (C-) fibers, respectively. The Neurometer is now widely used clinically to evaluate the effects of analgesic drugs and peripheral nerve function in various painful neuropathies including DPN [50, 64-66]. Twelve weeks after the induction of diabetes, diabetic mice showed hypoalgesia in CPTs at all stimuli with differential frequencies, and transplantation of ES-ABs improved these abnormalities. The aforementioned results were consistent with the results regarding the impaired IENFDs restored by the transplantation of ES-ABs in diabetic mice.

In conclusion, we have demonstrated the beneficial effects of transplantation of angioblast-like cells derived from ES cells on DPN. This ES-AB is relatively easy to obtain and can be repeatedly expanded to sufficient numbers for cell therapy. Although further studies designed to reveal other useful 


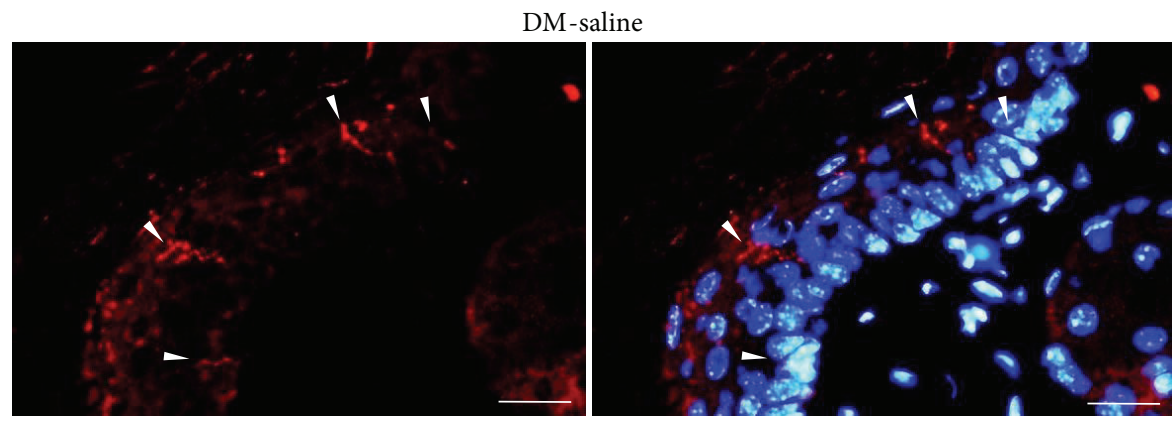

DM-ES-AB

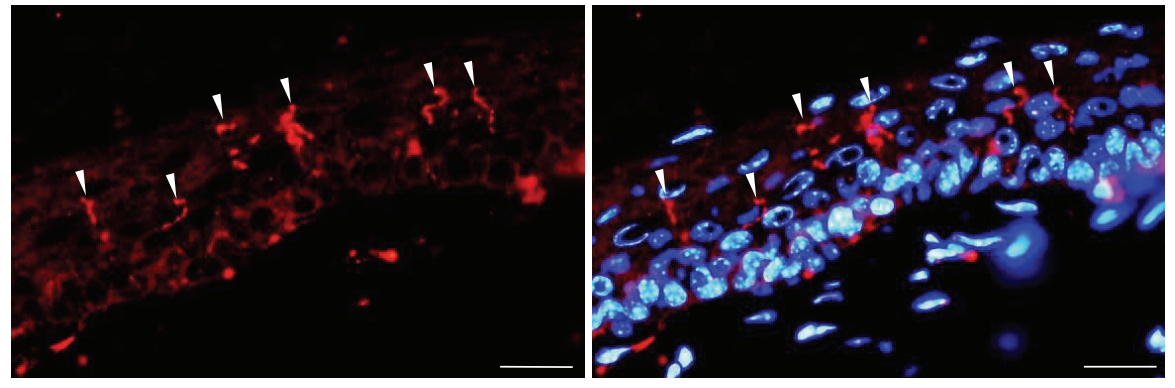

(a)

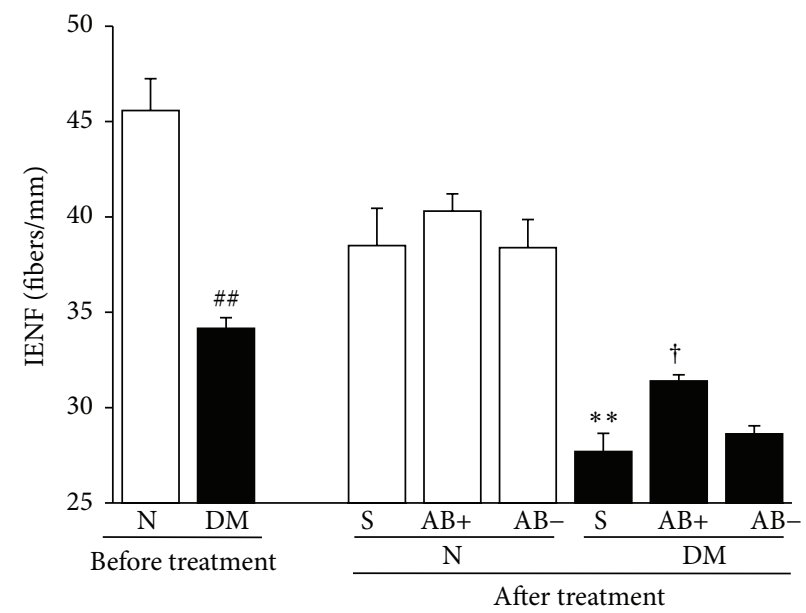

(b)

FIGURE 10: Intraepidermal nerve fibers (IENFs) were preserved by angioblast-like cells induced from ES cells (ES-ABs). (a) IENFs in plantar skins were visualized with PGP9.5 antibody (red). After 15 weeks of diabetes, IENF densities were decreased in diabetic mice (upper) and the impairment was restored by ES-ABs transplantation (lower). DM-saline: plantar skin of saline-injected limbs in diabetic mice and DM-ES-AB: plantar skin of limbs transplanted ES-ABs in diabetic mice. White arrowheads: IENFs. (b) Quantification of IENF densities demonstrated that IENFs were significantly decreased in diabetic mice compared with those in normal mice at 12 weeks of diabetes and this decrease was significantly ameliorated by transplantation of ES-ABs. However, administration of ES-ABs did not change IENF densities in normal mice. $\mathrm{N}$ : normal mice limbs, DM: diabetic mice limbs, S: saline-injected limbs, AB+: limbs transplanted ES-ABs, and AB-: contralateral limbs transplanted ES-Abs. Results are means \pm SD. ${ }^{\# \#} P<0.005$ versus pretreatment $\mathrm{N},{ }^{* *} P<0.005$ versus posttreatment $\mathrm{S}$-treated $\mathrm{N}$, and ${ }^{\dagger} P<0.05$ versus posttreatment $S$-treated DM. $n=3-4$ in each group.

aspects of ES-AB transplantation on DPN might be required, transplantation of angioblast-like cells induced from pluripotent cells appears promising as a novel therapeutic strategy for DPN.

\section{Conflict of Interests}

The authors declare that there is no conflict of interests regarding the publication of this paper. 


\section{Acknowledgments}

This research was supported in part by Grant-in-Aid for Scientific Research (21592506) from the Ministry of Education, Culture, Sports, Science and Technology (MEXT) and in part by the "Strategic Research AGU-Platform Formation (20082012)" Project for Private Universities: matching fund subsidy from MEXT of Japan. The authors thank Michiko Yamada, Keiko Shimamoto, Naoko Furukawa, Chikako Nagase, and Mayumi Katagiri for technical assistance, and they thank Minoru Tanaka in the Division for Medical Research Engineering, Nagoya University Graduate School of Medicine, for maintenance of the FACS instrument.

\section{References}

[1] F. Ismail-Beigi, T. Craven, M. A. Banerji et al., "Effect of intensive treatment of hyperglycaemia on microvascular outcomes in type 2 diabetes: an analysis of the ACCORD randomised trial," The Lancet, vol. 376, no. 9739, pp. 419-430, 2010.

[2] The Diabetes Control and Complications Trial Research Group, "The effect of intensive treatment of diabetes on the development and progression of long-term complications in insulindependent diabetes mellitus," The New England Journal of Medicine, vol. 329, no. 14, pp. 977-986, 1993.

[3] R. Turner, "Intensive blood-glucose control with sulphonylureas or insulin compared with conventional treatment and risk of complications in patients with type 2 diabetes (UKPDS 33)," The Lancet, vol. 352, no. 9131, pp. 837-853, 1998.

[4] D. K. Wilson, K. M. Bohren, K. H. Gabbay, and F. A. Quiocho, "An unlikely sugar substrate site in the 1.65 A structure of the human aldose reductase holoenzyme implicated in diabetic complications," Science, vol. 257, no. 5066, pp. 81-84, 1992.

[5] F. G. Soriano, L. Virág, P. Jagtap et al., "Diabetic endothelial dysfunction: the role of poly(ADP-ribose) polymerase activation," Nature Medicine, vol. 7, no. 1, pp. 108-113, 2001.

[6] I. Giardino, D. Edelstein, and M. Brownlee, "Nonenzymatic glycosylation in vitro and in bovine endothelial cells alters basic fibroblast growth factor activity: a model for intracellular glycosylation in diabetes," The Journal of Clinical Investigation, vol. 94, no. 1, pp. 110-117, 1994.

[7] K. Horie, T. Miyata, K. Maeda et al., "Immunohistochemical colocalization of glycoxidation products and lipid peroxidation products in diabetic renal glomerular lesions. Implication for glycoxidative stress in the pathogenesis of diabetic nephropathy," The Journal of Clinical Investigation, vol. 100, no. 12, pp. 2995-3004, 1997.

[8] M. Lu, M. Kuroki, S. Amano et al., "Advanced glycation end products increase retinal vascular endothelial growth factor expression," The Journal of Clinical Investigation, vol. 101, no. 6, pp. 1219-1224, 1998.

[9] A. M. Schmidt, O. Hori, J. X. Chen et al., "Advanced glycation endproducts interacting with their endothelial receptor induce expression of vascular cell adhesion molecule-1 (VCAM-1) in cultured human endothelial cells and in mice: a potential mechanism for the accelerated vasculopathy of diabetes," The Journal of Clinical Investigation, vol. 96, no. 3, pp. 1395-1403, 1995.

[10] M. Shinohara, P. J. Thornalley, I. Giardino et al., "Overexpression of glyoxalase-I in bovine endothelial cells inhibits intracellular advanced glycation endproduct formation and prevents hyperglycemia-induced increases in macromolecular endocytosis," The Journal of Clinical Investigation, vol. 101, no. 5, pp. 1142-1147, 1998.

[11] P. A. Craven, R. K. Studer, and F. R. DeRubertis, "Impaired nitric oxide-dependent cyclic guanosine monophosphate generation in glomeruli from diabetic rats. Evidence for protein kinase Cmediated suppression of the cholinergic response," Journal of Clinical Investigation, vol. 93, no. 1, pp. 311-320, 1994.

[12] H. Ishii, M. R. Jirousek, D. Koya et al., "Amelioration of vascular dysfunctions in diabetic rats by an oral PKC $\beta$ inhibitor," Science, vol. 272, no. 5262, pp. 728-731, 1996.

[13] D. Koya and G. L. King, "Protein kinase C activation and the development of diabetic complications," Diabetes, vol. 47, no. 6, pp. 859-866, 1998.

[14] P. Xia, R. M. Kramer, and G. L. King, "Identification of the mechanism for the inhibition of $\mathrm{Na}+, \mathrm{K}+$-adenosine triphosphatase by hyperglycemia involving activation of protein kinase $\mathrm{C}$ and cytosolic phospholipase A2," The Journal of Clinical Investigation, vol. 96, no. 2, pp. 733-740, 1995.

[15] V. Kolm-Litty, U. Sauer, A. Nerlich, R. Lehmann, and E. D. Schleicher, "High glucose-induced transforming growth factor betal production is mediated by the hexosamine pathway in porcine glomerular mesangial cells," The Journal of Clinical Investigation, vol. 101, no. 1, pp. 160-169, 1998.

[16] K. A. Kles and A. I. Vinik, "Pathophysiology and treatment of diabetic peripheral neuropathy: the case for diabetic neurovascular function as an essential component," Current Diabetes Reviews, vol. 2, no. 2, pp. 131-145, 2006.

[17] D. W. Zochodne, "Diabetes mellitus and the peripheral nervous system: manifestations and mechanisms," Muscle and Nerve, vol. 36, no. 2, pp. 144-166, 2007.

[18] S. Tesfaye, N. Chaturvedi, S. E. M. Eaton et al., "Vascular risk factors and diabetic neuropathy," The New England Journal of Medicine, vol. 352, no. 4, pp. 341-350, 2005.

[19] C. Giannini and P. J. Dyck, "Ultrastructural morphometric abnormalities of sural nerve endoneurial microvessels in diabetes mellitus," Annals of Neurology, vol. 36, no. 3, pp. 408-415, 1994.

[20] H. Yasuda and P. J. Dyck, "Abnormalities of endoneurial microvessels and sural nerve pathology in diabetic neuropathy," Neurology, vol. 37, no. 1, pp. 20-28, 1987.

[21] N. E. Cameron, M. A. Cotter, V. Archibald, K. C. Dines, and E. K. Maxfield, "Anti-oxidant and pro-oxidant effects on nerve conduction velocity, endoneurial blood flow and oxygen tension in non-diabetic and streptozotocin-diabetic rats," Diabetologia, vol. 37, no. 5, pp. 449-459, 1994.

[22] L. J. Coppey, J. S. Gellett, E. P. Davidson, J. A. Dunlap, D. D. Lund, and M. A. Yorek, "Effect of antioxidant treatment of streptozotocin-induced diabetic rats on endoneurial blood flow, motor nerve conduction velocity, and vascular reactivity of epineurial arterioles of the sciatic nerve," Diabetes, vol. 50, no. 8, pp. 1927-1937, 2001.

[23] T. Asahara, T. Murohara, A. Sullivan et al., "Isolation of putative progenitor endothelial cells for angiogenesis," Science, vol. 275, no. 5302, pp. 964-967, 1997.

[24] Y. Lin, D. J. Weisdorf, A. Solovey, and R. P. Hebbel, "Origins of circulating endothelial cells and endothelial outgrowth from blood," The Journal of Clinical Investigation, vol. 105, no. 1, pp. 71-77, 2000.

[25] M. Peichev, A. J. Naiyer, D. Pereira et al., "Expression of VEGFR2 and $\mathrm{AC} 133$ by circulating human $\mathrm{CD}^{+} 4^{+}$cells identifies 
a population of functional endothelial precursors," Blood, vol. 95, no. 3, pp. 952-958, 2000.

[26] M. C. Yoder, L. E. Mead, D. Prater et al., "Redefining endothelial progenitor cells via clonal analysis and hematopoietic stem/progenitor cell principals," Blood, vol. 109, no. 5, pp. 18011809, 2007.

[27] M. Massa, V. Rosti, M. Ferrario et al., "Increased circulating hematopoietic and endothelial progenitor cells in the early phase of acute myocardial infarction," Blood, vol. 105, no. 1, pp. 199-206, 2005.

[28] S. Shintani, T. Murohara, H. Ikeda et al., "Mobilization of endothelial progenitor cells in patients with acute myocardial infarction," Circulation, vol. 103, no. 23, pp. 2776-2779, 2001.

[29] J. George, A. Afek, A. Abashidze et al., "Transfer of endothelial progenitor and bone marrow cells influences atherosclerotic plaque size and composition in apolipoprotein E knockout mice," Arteriosclerosis, Thrombosis, and Vascular Biology, vol. 25, no. 12, pp. 2636-2641, 2005.

[30] Y.-S. Yoon, A. Wecker, L. Heyd et al., "Clonally expanded novel multipotent stem cells from human bone marrow regenerate myocardium after myocardial infarction," The Journal of Clinical Investigation, vol. 115, no. 2, pp. 326-338, 2005.

[31] M. L. Balestrieri, M. Rienzo, F. Felice et al., "High glucose downregulates endothelial progenitor cell number via SIRT1," Biochimica et Biophysica Acta, vol. 1784, no. 6, pp. 936-945, 2008.

[32] G. P. Fadini, M. Miorin, M. Facco et al., "Circulating endothelial progenitor cells are reduced in peripheral vascular complications of type 2 diabetes mellitus," Journal of the American College of Cardiology, vol. 45, no. 9, pp. 1449-1457, 2005.

[33] N. Kränkel, V. Adams, A. Linke et al., "Hyperglycemia reduces survival and impairs function of circulating blood-derived progenitor cells," Arteriosclerosis, Thrombosis, and Vascular Biology, vol. 25, no. 4, pp. 698-703, 2005.

[34] C. J. M. Loomans, E. J. P. de Koning, F. J. T. Staal et al., "Endothelial progenitor cell dysfunction: a novel concept in the pathogenesis of vascular complications of type 1 diabetes," Diabetes, vol. 53, no. 1, pp. 195-199, 2004.

[35] O. M. Tepper, R. D. Galiano, J. M. Capla et al., "Human endothelial progenitor cells from type II diabetics exhibit impaired proliferation, adhesion, and incorporation into vascular structures," Circulation, vol. 106, no. 22, pp. 2781-2786, 2002.

[36] O. Awad, C. Jiao, N. Ma, M. Dunnwald, and G. C. Schatteman, "Obese diabetic mouse environment differentially affects primitive and monocytic endothelial cell progenitors," Stem Cells, vol. 23, no. 4, pp. 575-583, 2005.

[37] K. A. Gallagher, Z.-J. Liu, M. Xiao et al., "Diabetic impairments in NO-mediated endothelial progenitor cell mobilization and homing are reversed by hyperoxia and SDF- $1 \alpha$," Journal of Clinical Investigation, vol. 117, no. 5, pp. 1249-1259, 2007.

[38] E. J. Marrotte, D.-D. Chen, J. S. Hakim, and A. F. Chen, "Manganese superoxide dismutase expression in endothelial progenitor cells accelerates wound healing in diabetic mice," The Journal of Clinical Investigation, vol. 120, no. 12, pp. 4207-4219, 2010.

[39] P. Koch, Z. Kokaia, O. Lindvall, and O. Brüstle, "Emerging concepts in neural stem cell research: autologous repair and cellbased disease modelling," The Lancet Neurology, vol. 8, no. 9, pp. 819-829, 2009.
[40] D. G. Phinney and D. J. Prockop, "Concise review: mesenchymal stem/multipotent stromal cells: the state of transdifferentiation and modes of tissue repair-current views," Stem Cells, vol. 25, no. 11, pp. 2896-2902, 2007.

[41] C. Stamm, B. Westphal, H.-D. Kleine et al., "Autologous bonemarrow stem-cell transplantation for myocardial regeneration," The Lancet, vol. 361, no. 9351, pp. 45-46, 2003.

[42] M. Chopp and Y. Li, "Treatment of neural injury with marrow stromal cells," The Lancet Neurology, vol. 1, no. 2, pp. 92-100, 2002.

[43] K. le Blanc, I. Rasmusson, B. Sundberg et al., "Treatment of severe acute graft-versus-host disease with third party haploidentical mesenchymal stem cells," The Lancet, vol. 363, no. 9419, pp. 1439-1441, 2004.

[44] K. Naruse, Y. Hamada, E. Nakashima et al., "Therapeutic neovascularization using cord blood-derived endothelial progenitor cells for diabetic neuropathy," Diabetes, vol. 54, no. 6 , pp. 1823-1828, 2005.

[45] J. E. Ferguson III, R. W. Kelley, and C. Patterson, "Mechanisms of endothelial differentiation in embryonic vasculogenesis," Arteriosclerosis, Thrombosis, and Vascular Biology, vol. 25, no. 11, pp. 2246-2254, 2005.

[46] R. L. Williams, D. J. Hilton, S. Pease et al., "Myeloid leukaemia inhibitory factor maintains the developmental potential of embryonic stem cells," Nature, vol. 336, no. 6200, pp. 684-687, 1988.

[47] G. Narazaki, H. Uosaki, M. Teranishi et al., "Directed and systematic differentiation of cardiovascular cells from mouse induced pluripotent stem cells," Circulation, vol. 118, no. 5, pp. 498-506, 2008.

[48] K. Watabe, T. Fukuda, J. Tanaka, H. Honda, K. Toyohara, and O. Sakai, "Spontaneously immortalized adult mouse Schwann cells secrete autocrine and paracrine growth-promoting activities," Journal of Neuroscience Research, vol. 41, no. 2, pp. 279-290, 1995.

[49] T. Shibata, K. Naruse, H. Kamiya et al., “Transplantation of bone marrow-derived mesenchymal stem cells improves diabetic polyneuropathy in rats," Diabetes, vol. 57, no. 11, pp. 3099-3107, 2008.

[50] J. J. Katims, E. H. Naviasky, L. K. Y. Ng, M. Rendell, and M. L. Bleecker, "New screening device for assessment of peripheral neuropathy," Journal of Occupational Medicine, vol. 28, no. 12, pp. 1219-1221, 1986.

[51] K. K. Beiswenger, N. A. Calcutt, and A. P. Mizisin, "Epidermal nerve fiber quantification in the assessment of diabetic neuropathy," Acta Histochemica, vol. 110, no. 5, pp. 351-362, 2008.

[52] H. Ishitobi, A. Wakamatsu, F. Liu et al., "Molecular basis for FlK1 expression in hemato-cardiovascular progenitors in the mouse," Development, vol. 138, no. 24, pp. 5357-5368, 2011.

[53] T. Iwase, N. Nagaya, T. Fujii et al., "Comparison of angiogenic potency between mesenchymal stem cells and mononuclear cells in a rat model of hindlimb ischemia," Cardiovascular Research, vol. 66, no. 3, pp. 543-551, 2005.

[54] T. Kinnaird, E. S. Burnett, M. Shou et al., "Local delivery of marrow-derived stromal cells augments collateral perfusion through paracrine mechanisms," Circulation, vol. 109, no. 12, pp. 1543-1549, 2004.

[55] I. Masaki, Y. Yonemitsu, A. Yamashita et al., "Angiogenic gene therapy for experimental critical limb ischemia: acceleration of limb loss by overexpression of vascular endothelial growth factor 165 but not of fibroblast growth factor-2," Circulation Research, vol. 90, no. 9, pp. 966-973, 2002. 
[56] M. Nakae, H. Kamiya, K. Naruse et al., "Effects of basic fibroblast growth factor on experimental diabetic neuropathy in rats," Diabetes, vol. 55, no. 5, pp. 1470-1477, 2006.

[57] P. Schratzberger, D. H. Walter, K. Rittig et al., "Reversal of experimental diabetic neuropathy by VEGF gene transfer," The Journal of Clinical Investigation, vol. 107, no. 9, pp. 1083-1092, 2001.

[58] P. Mårin, B. Andersson, M. Krotkiewski, and P. Björntorp, "Muscle fiber composition and capillary density in women and men with NIDDM," Diabetes Care, vol. 17, no. 5, pp. 382-386, 1994.

[59] J. M. Kennedy and D. W. Zochodne, "Influence of experimental diabetes on the microcirculation of injured peripheral nerve functional and morphological aspects," Diabetes, vol. 51, no. 7, pp. 2233-2240, 2002.

[60] D. W. Zochodne, "Nerve and ganglion blood flow in diabetes: an appraisal," International Review of Neurobiology, vol. 50, pp. 161-202, 2002.

[61] N. E. Cameron, M. A. Cotter, and S. Robertson, "Angiotensin converting enzyme inhibition prevents development of muscle and nerve dysfunction and stimulates angiogenesis in streptozotocin-diabetic rats," Diabetologia, vol. 35, no. 1, pp. 12$18,1992$.

[62] I. G. Obrosova, C. Van Huysen, L. Fathallah, X. Cao, M. J. Stevens, and D. A. Greene, "Evaluation of $\alpha 1$-adrenoceptor antagonist on diabetes-induced changes in peripheral nerve function, metabolism, and antioxidative defense," The FASEB Journal, vol. 14, no. 11, pp. 1548-1558, 2000.

[63] T. Okawa, H. Kamiya, T. Himeno et al., “Transplantation of neural crest-like cells derived from induced pluripotent stem cells improves diabetic polyneuropathy in mice," Cell Transplantation, vol. 22, no. 10, pp. 1767-1783, 2013.

[64] E. A. Masson, A. Veves, D. Fernando, and A. J. M. Boulton, "Current perception thresholds: a new, quick, and reproducible method for the assessment of peripheral neuropathy in diabetes mellitus," Diabetologia, vol. 32, no. 10, pp. 724-728, 1989.

[65] R. Matsutomo, K. Takebayashi, and Y. Aso, "Assessment of peripheral neuropathy using measurement of the current perception threshold with the neurometer in patients with type 2 diabetes mellitus," Journal of International Medical Research, vol. 33, no. 4, pp. 442-453, 2005.

[66] A. Veves, M. J. Young, C. Manes, and A. J. M. Boulton, "Differences in peripheral and autonomic nerve function measurements in painful and painless neuropathy: a clinical study," Diabetes Care, vol. 17, no. 10, pp. 1200-1202, 1994. 


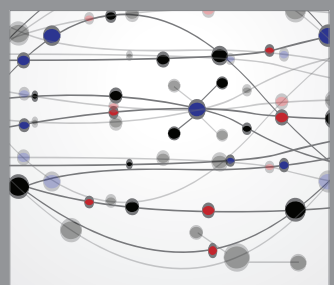

The Scientific World Journal
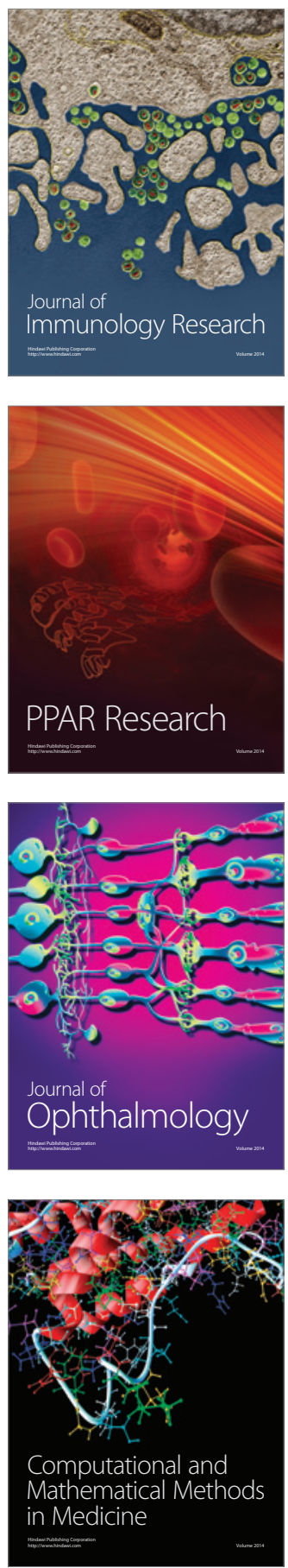

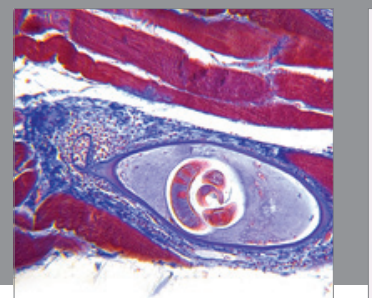

Gastroenterology

Research and Practice
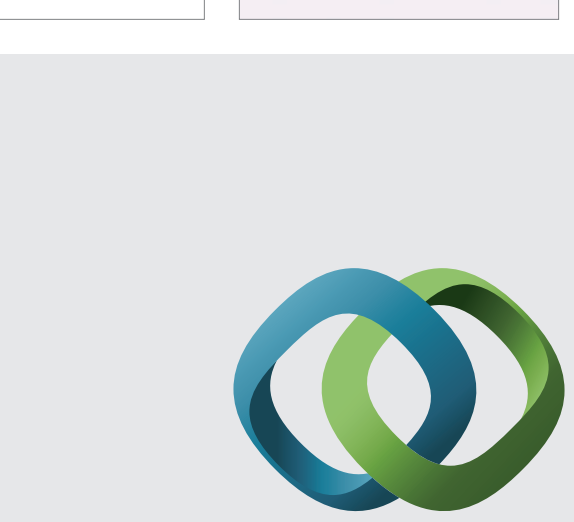

\section{Hindawi}

Submit your manuscripts at

http://www.hindawi.com
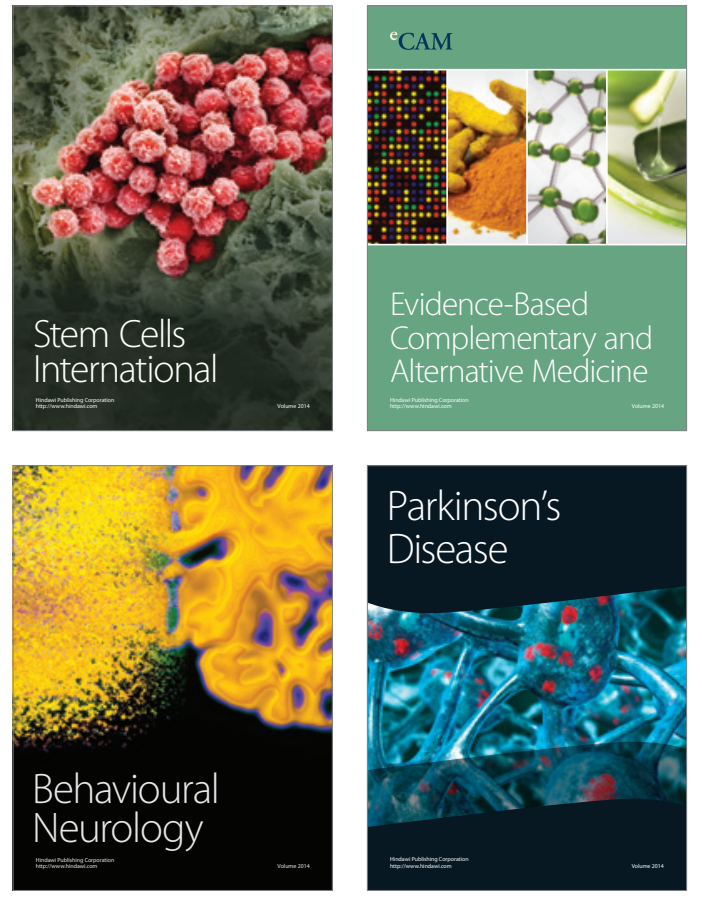
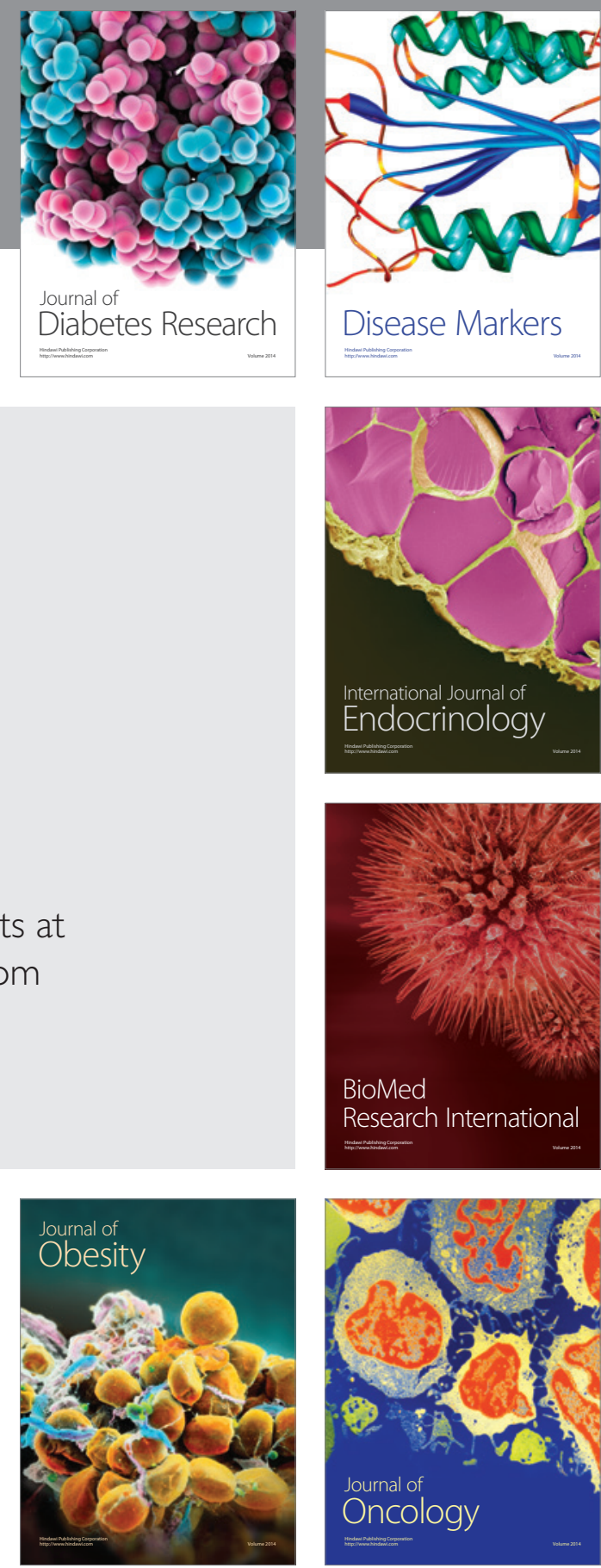

Disease Markers
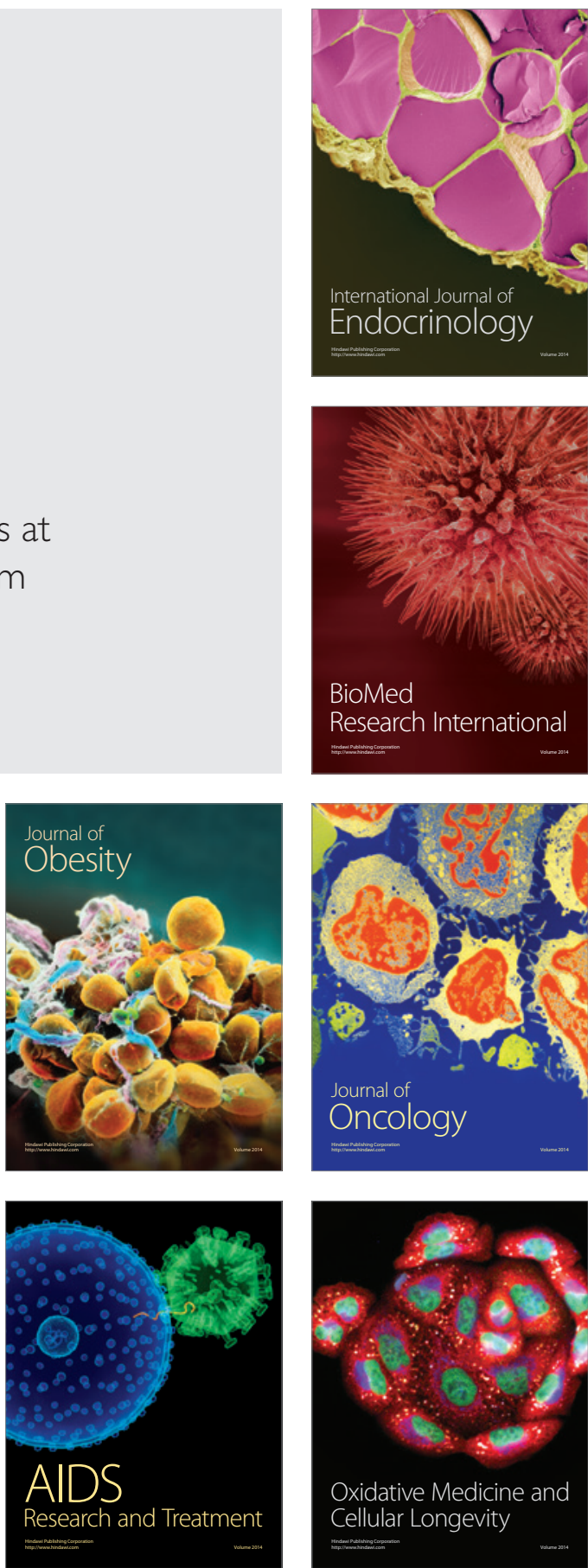